\title{
The Impact of Government Debt Supply on Bond Market Liquidity: An Empirical Analysis of the Canadian Market
}

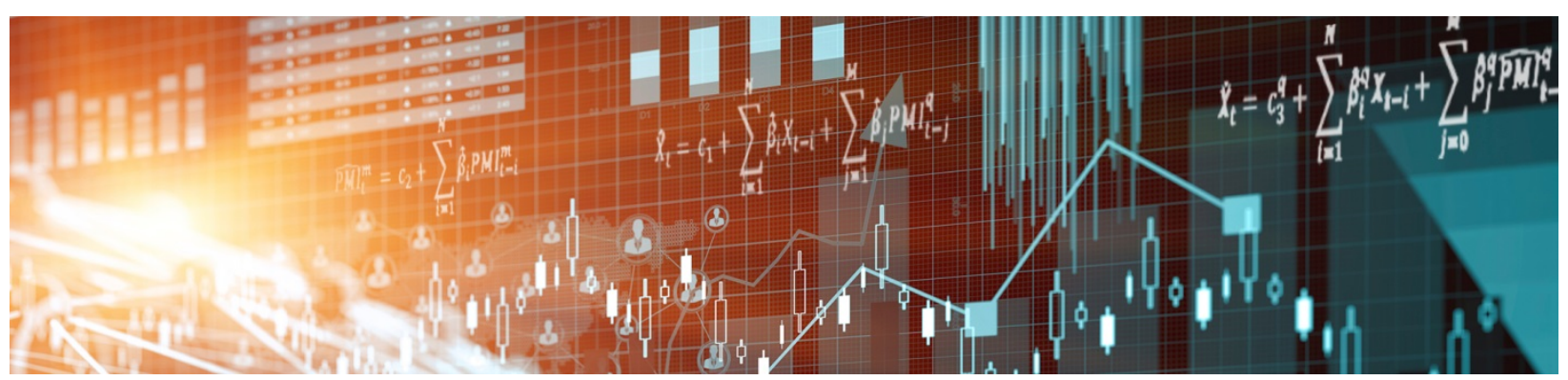

by Jeffrey Gao, Jianjian Jin and Jacob Thompson 
Bank of Canada Staff Working Paper 2018-35

July 2018

\title{
The Impact of Government Debt Supply on Bond Market Liquidity: An Empirical Analysis of the Canadian Market
}

\author{
by \\ Jeffrey Gao, ${ }^{1}$ Jianjian Jin ${ }^{1}$ and Jacob Thompson ${ }^{2}$ \\ ${ }^{1}$ Funds Management and Banking Department \\ Bank of Canada \\ Ottawa, Ontario, Canada K1A 0G9 \\ jgao@bankofcanada.ca \\ ïin@bankofcanada.ca \\ 20xford University
}




\section{Acknowledgements}

We are grateful for helpful comments from Narayan Bulusu, Francisco Rivadeneyra, Jun Yang and other seminar participants at the Bank of Canada. Special thanks go to Antonio Diez de los Rios, who provided significant help on this paper. Any errors are the responsibility of the authors. 


\begin{abstract}
This paper finds that Government of Canada benchmark bonds tend to be more illiquid over the subsequent month when there is a large increase in government debt supply. The result is both statistically and economically significant, stronger for the long-term than the short-term sector, and is robust when other macro factors are controlled for. The result is consistent with the interpretation that risk-averse dealers tend to provide less liquidity to the market when facing increased duration risks brought by large debt issuance. The fact that the newly issued bonds are much less liquid may also contribute to the impact of debt supply on market liquidity.

Bank topics: Asset pricing, Debt management, Financial markets

JEL codes: G, G1, G2, G12, G18, G32, D53
\end{abstract}

\title{
Résumé
}

Dans cette étude, les auteurs constatent que les obligations de référence du gouvernement du Canada sont généralement moins liquides dans le mois qui suit une forte hausse des émissions de titres de dette publique. Le résultat, qui est statistiquement et économiquement significatif, et plus probant à long terme qu'à court terme, se confirme lorsqu'on neutralise l'effet d'autres facteurs macroéconomiques. Ce résultat cadre avec la thèse selon laquelle des courtiers réfractaires au risque sont moins enclins à fournir des liquidités au marché lorsqu'ils encourent des risques de durée accrus en raison d'une importante émission de titres de créance. Le caractère beaucoup moins liquide des nouvelles obligations pourrait aussi contribuer à l'incidence des émissions des titres de dette sur la liquidité du marché.

Sujets : Évaluation des actifs, Gestion de la dette, Marchés financiers

Codes JEL : G, G1, G2, G12, G18, G32, D53 


\section{Non-Technical Summary}

Liquidity, defined as the degree to which a financial asset can be bought or sold easily without affecting its price, is an important indicator for the health and stability of financial markets. In this paper, we aim to understand better the dynamics of government bond market liquidity and their driving factors. In particular, we test the hypothesis that, following the government issue of more long-term bonds, the market liquidity for most of the currently actively traded bonds would be expected to drop. We find the results of this test to be both statistically significant and economically significant. We believe that our results can be explained both by dealers' limited risk-bearing capacity and by security fragmentation brought on by new bond issuance. Studies such as those by Greenwood and Vayanos (2014) and Lou et al. (2013) find strong evidence that the market-making dealers have limited risk-bearing capacity, such that an increase in the long-term government bond supply or the event of bond issuance can cause predictable market movements in even the most liquid financial markets such as that of the U.S. Treasury. The security fragmentation evidence is supported by the empirical fact that newly issued bonds are quite illiquid and tend to remain on primary dealers' balance sheets in the weeks after the bond auction. The duration and liquidity risks brought on by such new issuance may thus limit the dealers' capability to make the market for other actively traded bonds in the market.

Our results provide a useful lesson for both policymakers and academic researchers. For policymakers, our results show one mechanism whereby government debt management can impact secondary bond market liquidity. For academic researchers, our results complement the results of Greenwood and Vayanos (2014) and Lou et al. (2013) by showing that dealers' limited risk-bearing capacity has implications not only on market price movements but also on market liquidity. 


\section{Introduction}

Government bonds play an important role in a country's financial system. They form the basis for pricing many fixed-income securities and are widely used as collateral in core funding markets. Both functions require government bonds to be sufficiently safe and liquid. While on-the-run (or benchmark) sovereign bond securities in developed countries such as the U.S. and Canada are highly liquid in general, the level of the liquidity fluctuates over time and displays fragility during certain stress periods (e.g., see IMF, 2015). Therefore, understanding government bond market liquidity and its determinants is an important and active research topic among academics and policymakers.

While there have been extensive studies on government bond market liquidity from perspectives such as central bank monetary policy, financial regulations, and impact from other markets such as equity, relatively few directly investigate whether the government debt supply may play a role. Recently, Lou et al. (2013) and Fleming and Liu (2016) find temporary downward price movements for U.S. Treasury bonds around the time of auctions. Furthermore, Lou et al. (2013) find that when the total offering amount from all nearby Treasury auctions is large, the magnitude of the movement tends to be large as well. These findings can be interpreted as temporary price pressure effects due to dealers' limited risk-bearing capacity and investors' slow-moving capital. While one can infer that the Treasury market tends to be illiquid temporarily when debt supply is large, neither paper directly tests whether the Treasury market liquidity measures such as price impacts and bid-ask spreads are systematically affected by debt supply.

This paper directly examines whether government debt supply may affect bond market liquidity. The hypothesis that such a relationship exists is inspired by Greenwood and Vayanos (2014). They find that an increase in government debt supply leads to higher yields and higher expected returns for all government bonds, due to dealers' limited riskbearing capacity and a certain degree of market segmentation. A natural implication of their study is that all bonds become riskier when debt supply is large. Assuming that dealers typically are less willing to provide liquidity to trade when bonds are more risky, the liquidity condition would deteriorate as a result.

In testing such a hypothesis, we depart from existing studies in several important ways. First, we focus on the Canadian market. The Government of Canada has been

quite active in managing its debt supply over the past decade. While the average maturity remains stable at about 7 years, the total stock of the debt has increased significantly from 
$\$ 492$ billion in September 2009 to $\$ 634$ billion in August 2017. ${ }^{1}$ This significant timevariation in the total maturity-weighted debt provides an ideal test bed to see whether debt supply changes have any impact on market liquidity. Moreover, Canada adopts a different issuance strategy than the U.S., as it slowly builds newly issued bonds toward the benchmark status. ${ }^{2}$ In contrast, in the U.S. market, newly issued bonds become onthe-run immediately after issuance. As discussed below, such an institutional difference may suggest a different mechanism for debt supply to affect market liquidity. Since many OECD countries adopt a debt issuance strategy similar to Canada's, our findings should be applicable for many other sovereign bond markets as well. ${ }^{3}$

Second, instead of looking at temporary liquidity-related price pressure effects lasting for a few days, we look at a price impact measure similar to Amihud (2002) and we aggregate the daily measure over a month. Such a measure combines information from both price and trading volume and can capture market liquidity conditions more accurately than market price movements alone. This is because the former captures both the transitory and permanent price impact components when executing large-sized trades (Vayanos and Wang 2012) while the latter may only capture the transitory component. Furthermore, our modification ensures that the measure is robust against outliers.

Third, the debt supply measure we choose is a maturity-weighted debt supply containing all debt offered by the government and all the buybacks, as opposed to the amount of a single issuance or the size of the total government debt. Such a measure is aimed at better capturing the duration risks imposed on bond market makers in aggregate and has been found by studies such as Greenwood and Vayanos (2014) to be an important factor to predict bond returns.

Fourth, in terms of the investigation methodology, we adopt a regression-like framework, in contrast to Lou et al. (2013) and Fleming and Liu (2016), who conduct event studies. The regression framework allows us to investigate the impact from debt supply on market liquidity over a relatively longer horizon.

Fifth, similar to Lou et al. (2013) we consider the primary-secondary market fric-

\footnotetext{
${ }^{1}$ Throughout the paper we use the Canadian dollar as the denominating currency.

${ }^{2}$ The rationale for adopting such a strategy is that, if the government chooses to issue the full benchmark amount of a bond all at once, it may risk causing a large supply shock to the market and incurring high issuance costs.

${ }^{3}$ Similar strategies have been adopted by many other OECD countries, including Australia, Italy, New Zealand, Spain, and Sweden. The criteria we used for that is whether the country's most recent $10 \mathrm{Y}$ bond became the benchmark - defined as the generic $10 \mathrm{Y}$ bond used as a pricing point in its Bloomberg YCGT sovereign yield curve - after multiple issuances (instead of just one).
} 
tion to be important for explaining our findings. However, instead of relying on dealers' collective hedging demand, as they suggest, to interpret our results, we consider a fragmentation of liquidity due to new security issuance ("security fragmentation") to be key to explaining our findings. In particular, we believe that the market liquidity condition likely gets worse when dealers are busy absorbing duration risks from newly issued bonds. This happens because new bonds are generally difficult to trade and likely stay on dealers' books weeks after their issuance. This consequently diversifies away the capital and risk budgets that the dealers may otherwise allocate to trade other bonds in the market. While "security fragmentation" has long been recognized as a potential issue for market liquidity (see, e.g., Gravelle, 1998), our paper is the first to provide quantitative evidence to show its impact.

We test our hypothesis using high-frequency bond-trading data and find that the Government of Canada benchmark bonds tend to be more illiquid over the subsequent month when there is a large increase in government debt supply. The effect is stronger for the long-term maturity sectors (e.g., 10Y and 30Y sectors). Such a result is consistent with what has been found in existing studies on debt supply effect such as Greenwood and Vayanos (2014). Our result is statistically significant and robust across various sets of model specifications, control variables, measures of price impact, and measures of government debt supply changes. The result also holds against potential small-sample biases.

Our results are also economically significant. In the example of the $10 \mathrm{Y}$ sector, it suggests that after controlling for common macroeconomic factors such as the Canadian 10y-3m term spread, the U.S. CME VIX index, and the U.S. Treasury-EuroDollar (TED) spread, a one-standard-deviation increase in the 3-month average debt supply flows leads to about a $1.16 \mathrm{bps} /$ billion increase in the average price impact measure for the subsequent month. The magnitude of the coefficient is non-negligible given that normal-time price impact measures typically range from 5 to $15 \mathrm{bps} /$ billion. Moreover, it is comparable to that of the VIX index and the TED spread, suggesting that debt supply can affect market liquidity as strongly as these more recognized macro factors from monetary policy and global financial conditions. Therefore, a main takeaway from our results is that fiscal policy related to debt management can matter to financial market stability as much as monetary policy and stock market volatility.

We interpret our results to be consistent with the dealers' limited risk-bearing capacity combined with "security fragmentation". Besides showing that the trading volume 
of newly issued (non-benchmark) bonds is generally quite low and therefore the bonds are difficult to trade, we present two additional pieces of evidence to support our interpretation. First, the trading volume correlation between benchmark bonds and newly issued bonds is generally low and less than that between benchmark bonds and some off-the-benchmark bonds. This suggests that the newly issued bonds are quite illiquid and it is difficult for dealers to hedge the duration risks with benchmark bonds. Second, we find that, at least for the $10 \mathrm{Y}$ sector, price impact measures not only increase for the most liquid benchmark bond, but for other less-liquid, off-the-benchmark bonds as well, indicating that the withdrawal of market-making activity is prevalent in the bond market.

We also support the "security fragmentation" interpretation by testing alternative channels that might explain our findings. This includes testing the hedging channel as suggested by Lou et al. (2013), the new-benchmark channel and the seasonality channel. In general, we find none of them can fully explain what we find as satisfactorily as the "security fragmentation" interpretation.

From our tests, we believe the increased market price impact measure can be interpreted as the result of government debt supply shocks. While it is generally quite hard to infer an exact causal relationship with a conventional regression analysis as adopted by our study, we believe that the causality direction here is quite clear. The schedule and the approximate amount of the Government of Canada bond issuance are well known before auctions take place, and the regression is conducted in a predictive manner so that the endogeneity concern is minimized. Furthermore, other key macro factors that can affect market liquidity movements are controlled for, so that we can exclude the possibility that out results could be due to some spurious correlation between debt issuance and macro factors. Finally, our causal interpretation is qualitatively consistent with the theoretical and empirical findings of Greenwood and Vayanos (2014) and Lou et al. (2013).

The rest of the paper is arranged as follows: the rest of Section 1 discusses some of the related literature and the contribution of this paper; Section 2 presents the empirical setting; Section 3 presents the main empirical results; Section 4 provides our main interpretation for these results; Section 5 investigates alternative hypotheses; and Section 6 concludes. 


\section{Related Literature}

Our work is related to the literature on bond market liquidity. Compared with the equity market, bond market liquidity is a relatively small strand of literature due to the limitation of data resources. Some studies focus on how to best measure bond market liquidity in the context of a sovereign or corporate bond market. Fleming (2003) systematically examines different sovereign bond market liquidity measures in the context of the U.S. Treasury market. Schestag et al. (2016) examine various liquidity measures for the U.S. corporate bond market. Hu et al. (2013) and Fontaine and Nolin (2017) each construct bond liquidity indexes that reflect the degree of limit-to-arbitrage, which closely reflects the funding liquidity or liquidity risk premium in the bond market.

In terms of research on the determinants of market liquidity, Goyenko and Ukhov (2009) find that the liquidity condition tends to be affected by monetary policy and that the flight-to-liquidity or flight-to-quality effect explains the close linkage between stock and bond market liquidity. Christensen and Gillan (2017) find evidence that unconventional central bank monetary policy improves the bond market liquidity by increasing the bargaining power of sellers in the bond market and reducing the liquidity risk premium in the Treasury inflation-protected securities (TIPS) and inflation swaps. There is also a recently growing literature theoretically and empirically investigating whether tighter post-crisis financial regulations put more constraints on market makers' capacity and therefore reduce bond liquidity. For example, see Bao et al. (2016), Cimon and Garriott (2016), Trebbi and Xiao (2017), and Adrian et al. (2017a,b).

Our work is also related to the literature studying the impact of government debt supply on bond prices, both at the aggregate level and at the more granular, issuanceevent level. At the aggregate level, Greenwood and Vayanos (2014) show that increases in the government debt supply raise the government bond yields and expected returns. Krishnamurthy and Vissing-Jorgensen (2013) show that when the supply of U.S. government bonds is low, investors would value more the high liquidity and safety provided by the U.S. Treasuries, leading to higher corporate credit spreads. At the micro level, studies such as Lou et al. (2013) and Fleming and Liu (2016) link government bond auction events to predictable market price movements to show that, even for the most liquid markets such as the U.S. Treasury, there is a predictable temporary deviation from bond fundamental prices due to dealers' limited risk-bearing capacity and investor capital immobility.

Our study complements both the market liquidity literature and government debt 
supply literature by showing that: (1) government debt supply shocks can be an important driver for market liquidity movements as well, and (2) when a newly issued bond is illiquid, the effect of "security fragmentation" can be an important channel for reducing the market-making capability of risk-averse bond dealers.

Our study provides a motivation for studying bond dealers' inventory management behaviour in the Canadian market. While there has been an extensive literature investigating the dealer inventory issue in equity and foreign exchange markets (e.g., see Amihud and Mendelson, 1980), relatively few studies look at the fixed-income markets. The exceptions are Naik and Yadav (2003), who look at the dealers' behaviour in the U.K. market, and Fleming and Rosenberg (2008), who look at that in the U.S. Treasury market. While both papers find that dealers play an important role in bridging the primary and secondary markets, they also find such behaviours may vary across different markets. We leave more detailed investigations of the Canadian bond market dealers' behaviour to future studies.

Finally, our paper is related to the literature focusing on the Government of Canada bond market liquidity condition. Studies such as Gravelle et al. (1998, 1999) and D'Souza et al. (2003) provide empirical analysis for the microstructure of the bond market and the role dealers play in it. Our paper is the first to study the linkage between debt supply and market liquidity, particularly regarding the period after the financial crisis.

By shedding light on the role of large debt issuance in bond market liquidity, our study offers important lessons for both policymaking and bond investing. For example, our results suggests that if current market liquidity is affected by past large issuance, debt issuance cost may rise in the near future as a result. Moreover, the need to pay attention to the life cycle of the Canadian bonds and their interaction with the core funding market has been studied by Bulusu and Gungor (2017). Complementing this, our work provides empirical evidence that paying attention to the issuance cycle may also be crucial in reducing trading costs. 


\section{Empirical Setting}

\subsection{Background of the GoC bond market}

The Government of Canada (GoC) bond market consists of coupon-paying instruments that are originally issued primarily in the $2 \mathrm{Y}, 5 \mathrm{Y}, 10 \mathrm{Y}$, and $30 \mathrm{Y}$ sectors. ${ }^{4}$ In the secondary government bond market, each sector has a designated benchmark bond, which is typically a recently issued bond (though not necessarily the most recently issued) with time-to-maturity close to the sector's nominal term. As of August 2017, the total outstanding amount of nominal GoC bonds was $\$ 502$ billion, of which $\$ 61$ billion had benchmark status. ${ }^{5}$

Unlike U.S. Treasuries where newly issued bonds immediately become on-the-run (similar to benchmark status in Canada), a newly issued bond in Canada typically does not become the benchmark immediately. There are typically three types of bonds for a given sector: the benchmark, the off-the-benchmark, and the building-to-benchmark. Among the three types, benchmark bonds typically see the highest trading activity.

Figure 1 provides an illustrative example of the life cycle of $10 \mathrm{Y}$ sector bonds in the market. ${ }^{6}$ Let's label the centre blue block as the "current" period, the left blue block as the "previous" period, and the right blue block as the "next" period. A bond will typically experience "building-to-benchmark" status in the previous period, "benchmark" status in the current period, and "off-the-benchmark" status in the next period. As can be seen in the figure, the benchmark and the first off-the-benchmark bond, defined as the bond that had benchmark status before the current benchmark, are relatively more actively traded in the market. The building-to-benchmark bond typically sees very little trading in the early rounds of issuance, but its volume generally increases quickly shortly before it becomes the new benchmark bond.

\footnotetext{
${ }^{4}$ Although $3 \mathrm{Y}$ and $7 \mathrm{Y}$ benchmark bonds exist, the $3 \mathrm{Y}$ benchmark has not been regularly issued and there is no specific issuance for the $7 \mathrm{Y}$ benchmark. When there was no issuance, the $3 \mathrm{Y}$ benchmark was an existing bond with a similar time to maturity. The $7 \mathrm{Y}$ benchmark bond was usually the old $10 \mathrm{Y}$ benchmark bond.

${ }^{5}$ For more information, see https://www.fin.gc.ca/dtman/2016-2017/dmr-rgd17-eng.asp.

${ }^{6}$ For more institutional details of the Canadian bond market and an extensive investigation of the life cycle of usage of Canadian bonds in the core funding markets, see Bulusu and Gungor (2017).
} 


\subsection{Data of bond trading}

We collect data from the trading settlement dataset provided by CDS Clearing and Depository Services Inc., ${ }^{7}$ which covers all Government of Canada (GoC) bond trades executed in Canada over the sample period of September 2009 to August 2017. CDS records each transaction's instrument, trade and settlement date, entry timestamp, type (cash or repo), volume, and price. ${ }^{8}$

While the CDS dataset provides a fairly thorough coverage of GoC bond trading, it has some drawbacks. First, the timestamp of each trade is the time when it is entered into the CDS system, which is typically later than the actual trade. Second, there are no records of the bid-ask quotes in the CDS data. Therefore, it is hard to directly infer the effective bid-ask spreads, although such spreads can be inferred based on models such as Roll (1984).

To mitigate some of the limitations of the CDS dataset, we also obtain bond trading information from the dataset of CanDeal. CanDeal is the largest dealer-to-customer alternative trading messaging platform for GoC bonds in Canada, especially on the short end representing about $42 \%$ of the total benchmark bond market as of December 2015 . From July 2006 to December 2015, the data contain both intraday trading and quote data, allowing us to form a measure of effective bid-ask spreads. ${ }^{9}$ This measure serves two purposes: first, it is used to investigate whether the debt supply measure can predict bid-ask spread changes; second, the bid-ask spread is used to normalize the CDS Roll (1984) bid-ask measure, which is typically much larger in magnitude than the actual effective bid-ask spread.

Table 1 provides descriptive statistics for CDS trades. Overall, benchmark bonds are actively traded in the GoC cash market, with short-term bonds having a much higher

\footnotetext{
${ }^{7}$ Designated as a securities and derivatives clearing house under the Federal Payment Clearing and Settlement Act, CDS provides clearing services for Canada's equity, fixed-income and money markets. Most market participants in GoC bond trading are required to report their transactions to CDS. These reports contain the date, time (when entered into the system by the back office of the trader, typically 10 to 15 minutes later than the time when the actual trade takes place), type of trade (cash or repo), settlement date, volume, and price.

${ }^{8}$ We adopt a series of filtering criteria to clean the raw data. The transaction volume needs to be at least $\$ 100,000$ in par value. Trades need to be confirmed with realistic timing and prices. The entry date needs to be the same as the trade date and the entry time should be no later than 16:00 EST to ensure that no net trade reported by some other central clearing financial institution is included in the data.

${ }^{9}$ For the CanDeal dataset, which is in a relatively clean format, trades with a volume less than $\$ 100,000$ or an execution time later than 17:00 EST are removed. The most recent bid-ask quotes in terms of timestamp are used as the prevailing bid and ask prices for that trade.
} 
trading volume, turnover, and average trade size than long-term bonds. For example, regarding the average trade size, it is $\$ 25$ million/trade for $2 \mathrm{Y}$ bonds, more than six times that for $30 \mathrm{Y}$ bonds, which is about $\$ 4$ million/trade.

In developing the liquidity measures, we mainly rely on CDS to provide estimates on Amihud (2002) price impact measures given its rather complete coverage of the trading activity in GoC bonds. We also apply Roll (1984) methodology to calculate the implied bid-ask spread. Finally, we use transaction data from CanDeal to obtain the effective bid-ask spread measure from July 2006 to December 2015.

\subsection{Liquidity measure}

The primary measure of GoC bond liquidity in this paper is similar to Amihud (2002), which has a price impact interpretation (e.g., see Vayanos and Wang 2012). For a given month $t$, the measure is defined as the weighted average of daily price dispersion divided by trading volume:

$$
P I_{t}=\sum_{d=1}^{N} w_{d} \frac{\log \left(P_{d, 75 \%}^{V}\right)-\log \left(P_{d, 25 \%}^{V}\right)}{V_{d}}
$$

with $P_{d, 75 \%}^{V}$ and $P_{d, 25 \%}^{V}$ representing the volume-weighted top and bottom quartile price thresholds, respectively, $N$ representing the number of trading days over a month, $V_{d}$ representing the daily total trading volume, and $w_{d}$ representing the weighting on daily observations. In contrast to Amihud (2002), who uses the daily absolute return in the numerator, we use the price dispersion over a day to better capture the information available from the high-frequency data. ${ }^{10}$ Such a liquidity measure is also similar to the permanent component of the market impact formula suggested by Almgren et al. (2005).

Of the many ways of weighting the daily measure over a month, we choose the volume-

\footnotetext{
${ }^{10}$ Our use of the volume-weighted price dispersion also guarantees that the numerator is not affected by outlier trades whose prices either are far away from the market prevailing price or are simply reported mistakenly. While this may not matter much for liquid short- to medium-term benchmark bonds, for some of the off-the-benchmark bonds or lightly traded $30 \mathrm{Y}$ benchmark bonds, the difference can be quite large.
} 
weighted scheme. This means that our monthly measure can be calculated as

$$
\begin{aligned}
P I_{t} & =\sum_{d=1}^{N} \frac{V_{d}}{\sum_{d=1}^{N} V_{d}} \frac{\log \left(P_{d, 75 \%}^{V}\right)-\log \left(P_{d, 25 \%}^{V}\right)}{V_{d}} \\
& =\frac{\sum_{d=1}^{N} \log \left(P_{d, 75 \%}^{V}\right)-\log \left(P_{d, 25 \%}^{V}\right)}{\sum_{d=1}^{N} V_{d}} .
\end{aligned}
$$

This is also different from the original Amihud (2002) formula where measures across trading days are equally weighted. As discussed in the following section, volume-based weighting prevents small-volume trading days from dominating the price impact measure, which could be a particularly serious issue for the $30 \mathrm{Y}$ benchmark bonds or relatively illiquid off-the-benchmark bonds.

Another important measure of the CDS-based liquidity measure is the implied bidask spread based on Roll (1984), in which the (bid-ask) spread $S$ is proportional to the square root of the negative price change covariance, i.e.,

$$
S=2 \times \sqrt{-\operatorname{Cov}\left(\triangle p_{t+1, t}, \triangle p_{t, t-1}\right)},
$$

where $\triangle p_{t, t-1}$ is the price change from the $\mathrm{t}-1^{t h}$ to $\mathrm{t}^{\text {th }}$ transaction. ${ }^{11}$

The third measure is the effective bid-ask spread based on CanDeal, which is defined as

$$
\text { Effective Spread }=2 \times \frac{\left|P_{T}-M_{T}\right|}{M_{T}},
$$

where $P_{T}$ is the trade price and $M_{T}$ is the midpoint of bid and ask prices prevailing at the time of the trade.

Rows 4 to 6 in each of the sub-panels of Table 1 report summary statistics for benchmark bond liquidity measures. Measures of price impact and Roll spread (which has been normalized) are based on CDS from September 2009 to August 2017. The effective spread measure is based on CanDeal from September 2006 to December 2015.

Overall, the benchmark bonds, especially at the short end, are generally quite liquid; for example, the average $2 \mathrm{Y}$ benchmark effective bid-ask spread is only $0.7 \mathrm{bps}$ and even a large-sized transaction such as $\$ 1$ billion moves the price by little. As maturity

\footnotetext{
${ }^{11}$ With intraday data, one of the critical questions is choosing the length of the interval. We experiment with different sizes of time bars such as tick-by-tick, 2-minute, 5-minute, and 10-minute and find the results are essentially the same for all choices. Ultimately we choose the interval size to be 5 minutes.
} 
increases, the benchmark bond gets more illiquid with a higher bid-ask spread and a larger price impact, which is consistent with Goyenko and Ukhov (2009), who find that the transaction cost of a bond is positively related to duration or maturity.

Table 2 reports the monthly correlation between different liquidity measures across different sectors for the common sample period of September 2009 to December 2015. Overall, we can see that all measures are highly correlated, as they reflect the same trend in the market. Yet there could still be differences among different measures, which might be due to measurement errors (especially for the Roll measure) or different trading cost components (e.g., permanent vs. transitory) they reflect.

Figure 2 plots the time-series of the price impact measure, which shows a consistent improvement in market depth after the European debt crisis in the 2010-2011 period, with a small jump in 2013, which was likely due to Chairman Bernanke's "tapering" comment on May 22, 2013, and a slightly higher impact measure in 2014-2015 as oil prices dropped. Again, for the $2 \mathrm{Y}$ and $5 \mathrm{Y}$ sectors, the recent increases in illiquidity are relatively minor, in contrast, for the $10 \mathrm{Y}$ and $30 \mathrm{Y}$ sectors, the increases are more salient.

\subsection{Government debt supply measures}

To construct the measure of government debt supply, we start by constructing the maturity-weighted debt-to-GDP ratio in the same vein as Greenwood and Vayanos (2014):

$$
\begin{aligned}
\left(\frac{M W D}{G D P}\right)_{t} & =\frac{\sum_{0<\tau \leq 30} D_{t}^{(\tau)} \tau}{G D P_{t-3}} \\
& =M_{t} \frac{\sum_{0<\tau \leq 30} D_{t}^{(\tau)}}{G D P_{t-3}}
\end{aligned}
$$

where

$$
M_{t}=\frac{\sum_{0<\tau \leq 30} D_{t}^{(\tau)} \tau}{\sum_{0<\tau \leq 30} D_{t}^{(\tau)}} .
$$

This is essentially the dollar duration of the outstanding debt of a country divided by GDP for the most recent quarter. We then define the 3-month debt supply changes as

$$
\Delta(M W D / G D P)_{3 M, t}=\log \left(\frac{M W D}{G D P}\right)_{t}-\log \left(\frac{M W D}{G D P}\right)_{t-3}
$$

We focus on the "flow" effect of the debt supply instead of the "stock" effect. This is 
partly because debt-to-GDP ratio is quite persistent over the sample period, thus directly testing the stock effect would be challenging. More importantly, the flow effect can be directly linked to the impact of issuance on market liquidity, which is what we hypothesize based on Greenwood and Vayanos (2014). The advantage of using the maturity-based weighting scheme is that it can aggregate bonds with different maturities and has a clear connection with duration risks. As long-term bonds are much more risky than shortterm bonds, for the same par amount, the former should carry more weight in affecting a bond dealer's decision than the latter. Furthermore, normalization by GDP facilitates comparison between periods with high and low GDP levels, which generally is a better measure than using debt issuance alone (although it might not matter materially in our case since the GDP growth in our sample period is quite stable).

The changes in the debt-to-GDP ratio can be understood as approximately being contributed by average maturity changes, debt stock changes, and GDP changes, i.e.,

$$
\Delta(M W D / G D P)_{3 M, t} \approx \frac{\Delta M_{3 M, t}}{M_{t-3}}+\frac{\sum_{0<\tau \leq 30} \Delta D_{3 M, t}^{(\tau)}}{\sum_{0<\tau \leq 30} D_{t-3}^{(\tau)}}-\frac{\Delta G D P_{3 M, t}}{G D P_{t-3}}
$$

The 3-month change in the debt-to-GDP ratio mainly consists of three parts: the first part is due to the maturity changes brought by new issuance and maturity reduction or redemptions of the existing bond debt; the second part is due to the new issuance (publicly auctioned or syndicated), buybacks, or redemptions of the debt; the third part is due to the change in GDP over the 3 -month period. ${ }^{12}$

Panel A of Figure 3 illustrates $\triangle M W D / G D P_{3 M, t}$ before and after the financial crisis, with the blue-shaded area indicating the sample period covered in our study. As shown, there was a fast increase in the ratio through late-2008 to 2009 as the government quickly ramped up its debt issuance in response to the financial crisis and the GDP shrank during that time as well. Since then, the level of the debt supply changes has reverted mostly to the pre-crisis level. There was also a surge in the debt supply in 2014, when the government issued several rounds of $10 \mathrm{Y}$ and $30 \mathrm{Y}$ bonds and also issued for the first time a $50 \mathrm{Y}$ ultra-long bond. The significant changes in debt supply are in sharp contrast to the periods before the financial crisis, when debt supply was quite regular.

Panel B shows the 3-month changes in the level of the maturity-weighted debt (MWD) supply, the total duration-weighted debt issuance, and its short-term, medium-term, and

\footnotetext{
${ }^{12}$ Syndicated issuance refers to the issuance procedure whereby a group of primary dealers is paid to help sell the newly issued bonds and commits to buying what is left.
} 
long-term components. The key difference between the total maturity-weighted debt and the public-issued duration-weighted debt is that the former reflects syndicated issuance, buybacks and the declining maturity of the current stock of government debt, while the latter only reflects the auction-issued debt. ${ }^{13}$ As can be seen, the movements between total maturity-weighted debt changes and publicly issued duration-weighted debt (DWD) changes are highly correlated. Furthermore, most of the movements in DWD measure are driven by long-term issuance.

This close connection between debt supply changes and issuance is important to answer the question of whether it is appropriate to explain the aggregate debt supply effect by looking at institutional details at the issuance level. In theory, the aggregate debt supply and issuance do not have to be related. On the one hand, during periods without public issuance, the maturity-weighted debt supply may change due to the reduced maturity of the existing debt, private placements of debt, or buyback programs. On the other hand, even with public debt issuance, the debt supply may remain constant, as the increased duration risks brought by the debt supply are fully offset by the shortend redemption and the decline of the existing debt stock maturity. However, given that aggregate changes in a maturity-weighted government debt supply are statistically closely related to maturity-weighted public debt issuance, investigating the segmentation brought by issuance is relevant for explaining the effects of aggregate supply.

\subsection{Other macro factors}

Besides the debt supply factor, we also consider the following macro factors as the controlling factors for market liquidity. For baseline controlling factors, we consider the term spread of the GoC interest rate curve, defined by the difference between the $10 \mathrm{Y}$ and 3 -month zero-coupon bond yield; the TED spread, defined as the difference between the rate of interbank loans (3-month LIBOR rate) and the U.S. 3-month T-bill yield; and the VIX index, which characterizes the degree of risk aversion in the global financial market. These factors represent the key systemic risk factors facing the bond dealers when making markets. For robustness checks, we consider the CDOR spread, defined similarly to the TED spread but based on the Canadian interbank loan rate, and the Canadian swap spread, defined as the spread between the $10 \mathrm{Y}$ swap rate and the $10 \mathrm{Y}$ bond yield in the

\footnotetext{
${ }^{13}$ Instead of calculating the maturity-weighted debt issuance, here we adopt a slightly different formula by using the duration data available from the Government of Canada auction system. The two measures are similar (Greenwood and Vayanos 2014).
} 
Canadian market. All summary statistics of these factors are reported in Table 3.

\section{Main Results}

\subsection{Unconditional sorting}

To explore a simple relationship between bond price impact and $\Delta \mathrm{MWD} / \mathrm{GDP}_{3 M}$, we sort the sample period into five buckets based on the $\Delta \mathrm{MWD} / \mathrm{GDP}_{3 M}$ measure and calculate the sample average of price impact for each bucket.

The result, shown in Figure 4, reveals an interesting relationship between price impact and debt supply increase. For all sectors, the group with the highest average $\Delta \mathrm{MWD} / \mathrm{GDP}_{3 M}$ also has the highest average price impact. For example, in the $10 \mathrm{Y}$ sector, the group with the bottom $\Delta \mathrm{MWD} / \mathrm{GDP}_{3 M}$ has an average of $11 \mathrm{bps} / \mathrm{billion}$ price impact measure, while the highest quintile group has an average of 15 bps/billion price impact measure. A simple hypothesis test also suggests that, at least for the $10 \mathrm{Y}$ and $30 \mathrm{Y}$ sectors, the difference between the bottom and the top groups is statistically significant at the $5 \%$ level. Such a simple relationship serves as a good motivation to test if the relationship is robust against controlling for other factors.

\subsection{Basic regression}

We use the first-order autoregressive predictive model to test our main hypothesis. The model is in the following form:

$$
P I_{t}=A_{0}+A_{1} P I_{t-1}+A_{2} \Delta M W D / G D P_{3 M, t-1}+A_{3} \mathbf{Z}_{t-1}+\varepsilon_{t},
$$

where $P I_{t}$ represents the price impact measure for month $t ; \Delta \mathrm{MWD} / \mathrm{GDP}_{3 M, t-1}$ represents the 3-month changes in the maturity-weighted debt-to-GDP ratio at the end of month $t-1$; and $\mathbf{Z}_{t-1}$ represents the vector of exogenous factors such as term spread, VIX, etc. To facilitate comparison across different predicting variables, all regressors (including the debt supply measure) are normalized to have zero mean and unit standard deviation over the sample period (2009-2017). ${ }^{14}$

\footnotetext{
${ }^{14}$ To simplify, we do not report the case when $\Delta \mathrm{MWD} / \mathrm{GDP}_{t-1}$ is used as the sole predictor aside from $P I_{t-1}$. Our unreported result suggests that it yields qualitatively the same result as reported in Figure 4.
} 
There are many ways to specify the model regarding selecting macro factors. Here we choose a step-wise strategy by starting with the case when there are only $P I_{t-1}$ and the term spread in the model, then adding one by one the TED spread, VIX, and finally $\triangle \mathrm{MWD} / \mathrm{GDP}_{3 M, t-1}$ in order to show the incremental predictive power brought by each factor. For all regressions, we apply the standard Newey-West standard errors with a 12-month lag to adjust the significance level of regression coefficients. We also report the adjusted $\mathrm{R}^{2}$, $\mathrm{AIC}$, and $\mathrm{BIC}$ to assess whether based on statistical model selection criteria, debt supply measure indeed improves the in-sample predictive power for bond price impact.

Table 4 reports the regression results for benchmark bonds for the four sectors $(2 \mathrm{Y}$, $5 \mathrm{Y}, 10 \mathrm{Y}$ and $30 \mathrm{Y}$ ). Across all sectors, we first find significantly positive coefficients for the term spread and VIX, which is consistent with the intuition that both variables affect risk-averse dealers' ability and willingness to make the bond market. We do not find any predictive power from the TED spread that represents the level of funding liquidity in the global financial market. This is possibly due to the fact that during the sample period (2009-2017), the TED spread is generally compressed, therefore playing a smaller role in affecting market liquidity than during the 2008-2009 crisis period.

Our central finding is that the coefficients for $\Delta \mathrm{MWD} / \mathrm{GDP}_{3 M, t-1}$ are statistically significant for all sectors. The sizes of the coefficients are economically significant as well. For example, for the $10 \mathrm{Y}$ sector, the coefficient suggests that a $1 \sigma$ increase in the measure forecasts a $1.16 \mathrm{bps} /$ billion extra increase in the price impact measure over the next month after controlling for its own lag and other macro variables. ${ }^{15}$ As shown in Figure 2, in the past few years, the price impact measure typically ranges between 5 to 15 bps/billion; therefore, a non-negligible time variation in price impact can be explained by debt supply changes. Compared with coefficients on other predictors like term spread or VIX, the coefficient of $\Delta \mathrm{MWD} / \mathrm{GDP}_{3 M, t}$ is similar in size, indicating that impact from the debt supply side can be as important as impact from the monetary or financial condition side.

At the bottom of each sub-panel, we can also see the improved model predictive performance based on the adjusted $\mathrm{R}^{2}$, the Akaike information criterion (AIC), and the Bayesian information criterion (BIC) when $\Delta \mathrm{MWD} / \mathrm{GDP}_{3 M, t-1}$ is added. This suggests

\footnotetext{
${ }^{15}$ Note that the top and bottom $20 \%$ groups in terms of $\Delta \mathrm{MWD} / \mathrm{GDP}_{M A 3, t-1}$ on average have a difference of close to $3 \sigma$, implying a $3.5 \mathrm{bps} /$ billion difference. So the regression result is generally consistent with what is suggested in Figure 4.
} 
that from the statistical model selection perspective, supply measure should be included as a predictive factor too, especially for the $10 \mathrm{Y}$ and $30 \mathrm{Y}$ sectors.

To investigate further where the predictive relationship comes from, we replace the composite measure of $\Delta \mathrm{MWD} / \mathrm{GDP}$ by the duration-weighted debt issuance at the short, medium, and long parts of the yield curve, respectively. The short and medium issuance corresponds to the $2 \mathrm{Y}$ and $5 \mathrm{Y}$ sectors, respectively. For the long end, since we only have very few issuance data in the $30 \mathrm{Y}$ sector, we combine the $10 \mathrm{Y}$ and $30 \mathrm{Y}$ issuances together.

The result, reported in Table 5, illustrates clearly that it is the issuance in the longterm sector that mainly drives our results. For example, in the long-term sector, the coefficient is $0.83 \mathrm{bps} /$ billion, which is slightly smaller than that in Table 4, probably due to the fact that some of the largest private long-bond issuances (e.g., the privately issued 50Y bond in 2014) are not included in the long sector public issuance. However, the general pattern clearly suggests that the long-term sector issuance dominates shortto medium-term sectors in predicting price impact measures.

Since the Amihud (2002) price impact measure is the ratio between price dispersion and trading volume, a natural question is whether it is the trading volume or price dispersion term that is predicted by debt supply changes. To answer such a question, we run a regression of (log) trading volume and price dispersion on the same set of macro factors as in Table 4 . The result in Table 6 suggests that a higher $\Delta \mathrm{MWD} / \mathrm{GDP}$ typically predicts lower trading activity in the next month, while the price dispersion term does not. Therefore, it is the lower trading activity that drives the higher price impact after increases in debt supply.

\subsection{Other liquidity measures (bid-ask spread, Roll spread)}

We also consider other bond liquidity measures such as the effective bid-ask spread and the Roll (1984) implied bid-ask spread. We generally find our results to be weaker for these liquidity measures, probably due to large measurement errors or to the different aspects of market liquidity these measures reflect.

For the Roll (1984) measure, we find that the coefficient varies from being marginally significant to significant for the $10 \mathrm{Y}$ sector, depending on the measures of the regressor (MWD/GDP, MWD, or 3-month maturity-weighted issuance). For other sectors, the coefficients are not statistically significant. For the effective bid-ask spread measure 
(based on the CanDeal data from 2006 to 2015), we find no predictive relationship with debt supply changes. ${ }^{16}$

There are several possible reasons for the weaker connection between these liquidity measures and debt supply changes. Measurement error may be one factor. For example, the Roll measure requires a large amount of data and is calculated with significant noise due to the imperfect timestamp from the CDS data, which can explain why the result is more significant for the $10 \mathrm{Y}$ sector. ${ }^{17}$

Alternatively, it is also possible that these measures reflect different aspects of the market. As suggested by Vayanos and Wang (2013), while the Amihud (2002) measure reflects both the permanent and transitory components of trading price impacts, the Roll (1984) spread may reflect only the temporary component and the effective bid-ask spread may reflect only the trading cost of relatively small-sized trades. It is possible that it is only the permanent component that is more sensitive to changes in the government debt supply. We leave these issues for future research.

\subsection{Robustness}

We conduct a variety of robustness tests with different debt-supply measures, price impact measures, control variable sets, and regression methods. All results suggest that the predictive relationship between the debt supply and the bond price impact measure is robust, particularly for the $10 \mathrm{Y}$ and $30 \mathrm{Y}$ sectors.

- Alternative debt supply measure

Table 7 reports the regression results when alternative debt supply measures are used as predicting variables. Such alternative measures include (1) the debt supply changes that are not normalized by GDP, and (2) the total duration-weighted public issuance over the past 3 months, which does not include some of the ultra-long bond issuance and debt buybacks. Overall, we find the results to be unaffected by these alternative measures. $^{18}$

\footnotetext{
${ }^{16}$ Due to space limitation, these results are not reported here but are available upon request.

${ }^{17}$ As suggested in the previous table, the most significant results exist in the long-term sector. Thus, the reason we do not see any result in the $2 \mathrm{Y}$ and $5 \mathrm{Y}$ sectors is that the measurement noise quickly overshadows the small predictability resulting from debt supply shocks. For the $30 \mathrm{Y}$ sector, the issue is that it is quite lightly traded, so even though the predictability is strong, the noise in the Roll measure overshadows the statistical result.

${ }^{18}$ In an unreported study, we also consider individual month's maturity-weighted issuance as a predictive variable. Such a variable is much noisier than the 3 -month moving average. Yet we still find a
} 
- Alternative price impact measure

We also test whether different ways to calculate the price impact may change the conclusion. In particular, we consider three other price impact measures. PI01 is a measure following the original Amihud (2002) format, for which we first calculate the ratio between the absolute return over a day and the daily trading volume and then average over a month. PI02 is obtained by first calculating the price differential between top quartile price and bottom quartile price and then dividing it by daily trading volume before equally averaging over a month. PI03 is similar to PI02, except that the weighting over a month is based on daily trading volume. The results are reported in Table 8.

In general, we find that how the nominator is calculated, whether based on daily return or price dispersion, plays little role. However, how daily measures are averaged over a month matters for the $30 \mathrm{Y}$ sector, probably because some days with small trading volume contribute disproportionately to the final results in the equal-weighting case. In particular, we find that for the $30 \mathrm{Y}$ sector, the volume-weighted price impact measure can be predicted by debt supply but the equal-weighted measure cannot. We argue that price impacts on days with small trading volume are estimated with a high degree of uncertainty; therefore, a volume-weighted measure should be more appropriate. For all other sectors, the regression results are similar between volume-weighted and equalweighted price impact measures.

- More controlling factors

Table 9 checks whether including other financial variables will affect our results. We consider adding each of the following variables into the regression: 3-month T-bill yield, CDOR spread, swap spread. None of these variables change the conclusion of our previous results. $^{19}$

- Alternative regression models and bootstrap

We consider different model specifications to test the robustness of our results. In particular, we consider the possibility that the error term in the regression is highly correlated so that the regression coefficient may be biased. To check that, several different ARMA models are estimated with the results reported in Panel A of Table 10. Except for the $\operatorname{ARMA}(2,2)$ case for the $2 \mathrm{Y}$ sector, none of our results are affected.

significant relationship for the long-term sector. For brevity, we won't report the result here.

${ }^{19}$ Details are not reported here for brevity, but are available upon request. 
To account for the fact that we have a relatively small sample, we apply various bootstrap methods to calculate the confidence interval of the regression coefficient on $\triangle \mathrm{MWD} / \mathrm{GDP}_{3 M}$. Similar methods have been adopted by Greenwood and Vayanos (2014) in their context. We choose the number of draws of 10,000 and report the result in Panel B of Table 10. The first two columns are based on drawing a fixed-length (12-month or 24-month) block to conduct the non-parametric bootstrap. The third and fourth columns are based on a geometrically distributed block length centering around 12 and 24 months. The last column is based on the parametric bootstrap method (Davison and Hinkley 1997). The result shows that all of our conclusions remain unchanged.

\section{Interpretation}

We believe that a combination of dealers' limited risk-bearing capacity and the "security fragmentation" brought by the Government of Canada's benchmark-building strategy best explains our empirical results. To further strengthen our argument, we present two pieces of evidence based on examining illiquidity of newly issued bonds and price impact changes of off-the-benchmark bonds after debt supply changes.

Our first piece of evidence is from the basic liquidity profile of the building-tobenchmark bond compared with benchmark and off-the-benchmark bonds. Panel A of Table 11 reports the trading volume and Amihud (2002) price impact statistics for each sector's building-to-benchmark bond, 1st off-the-benchmark bond (benchmark in the last cycle), 2nd off-the-benchmark bond (benchmark in the issuance cycle before the last), and 3rd off-the-benchmark bond (benchmark in two cycles before). Overall, the trading activity for the building-to-benchmark bonds is very low compared to the benchmark sector. For the $10 \mathrm{Y}$ sector, the focus of our study, it can also be seen that the trading volume is so low that the price impact is not only much higher than the 1st off-the-benchmark bond, but is even higher than 2nd and 3rd off-the-benchmark bonds as well. This confirms the high illiquidity of building-to-benchmark bonds.

Furthermore, the correlation between newly issued and benchmark bonds is much lower than that between 1st off-the-benchmark and benchmark bonds. Panel B of Table 11 reports the average daily trading volume correlation between $10 \mathrm{Y}$ benchmark and building-to-benchmark and off-the-benchmark bonds, respectively. While there seems to be a close connection between benchmark trading and off-the-benchmark trading, with the daily correlation coefficient typically around 0.6 , there is a much weaker connection 
between benchmark and building-to-benchmark bonds, with the daily correlation only around 0.35. The difference is also statistically significant based on Lawley's (1963) Chi test. This is also consistent with our theory that because of the high illiquidity of newly issued bonds, it is difficult for traders to use current benchmark bonds to hedge the increased duration risks associated with debt issuance.

We also test if debt supply affects liquidity for bonds beyond the benchmark ones. Again, we focus on the 1st off-the-benchmark 10Y sector here. Table 12 illustrates that the price impact of the 1st off-the-benchmark $10 \mathrm{Y}$ bond increases following government debt issuance. And the results are robust for different measures of debt supply, including $\Delta \mathrm{MWD} / \mathrm{GDP}_{3 M}, \Delta \mathrm{MWD}$, maturity-weighted issuance, and maturity-weighted issuance at the sector level.

We also find that the 3rd off-the-benchmark $10 \mathrm{Y}$ bonds' market price impact can be predicted by debt supply changes. For the 2nd off-the-benchmark, we find it difficult to establish the case but we think this is due to other factors. The 2nd off-the-benchmark $10 \mathrm{Y}$ bond is somewhat unique as it is typically the cheapest-to-deliver bond in the $10 \mathrm{Y}$ bond futures market. Its trading activity is therefore heavily affected by the bond futures market trading cycle, which could potentially distort our results. ${ }^{20}$ Overall, we believe it is supported in our data and that, at least in the $10 \mathrm{Y}$ sector, the dealers make less market for bonds beyond the current benchmarks following large debt issuance.

\section{Alternative hypotheses}

\subsection{Dealer hedging demand}

We test whether the (relative) reduction of market trading activity is due to the contemporaneous surge of trading volume that is followed by regression-toward-the-mean in trading activity for the next month. The likely reason for the contemporaneous surge in benchmark bond trading activity is that dealers are trading a high volume of benchmark bonds to hedge their incoming duration risks, as found by Lou et al. (2013).

We reject this hypothesis for two reasons. First, based on Table 11, the trading correlation between benchmark and building-to-benchmark bonds is low on average, indicating that there is no widespread hedging using benchmark bonds when dealers have a large inventory of building-to-benchmark bonds. Second, in a contemporaneous regression of

\footnotetext{
${ }^{20}$ For brevity, such results are available upon request.
} 
10Y-benchmark trading volume on same-month debt issuance, the sign is negative (Table 13). So instead of finding a surge in volume around the auction date, market makers start to reduce their trading activity the same month when issuance takes place, contradictory to what the hedging demand interpretation would suggest. ${ }^{21}$

\subsection{New-benchmark effect}

Another possible explanation of our results is the new-benchmark effect. As illustrated in Figure 1, whenever the building-to-benchmark bond becomes the new benchmark following its last issuance, there is a surge in trading activity. Therefore, there might be a new-benchmark effect such that the price of the new benchmark bond also moves quickly when active trading of the bond begins, causing an increase in the price impact. Since the new-benchmark month typically sees one to two rounds of issuance in the three months before that, there might be a positive, yet mechanical relationship between changes in debt supply and changes in the bond market price impact measure.

We investigate this hypothesis by adding the dummy of the new-benchmark month in the regression together with an interaction term with $\Delta \mathrm{MWD} / \mathrm{GDP}_{3 M, t-1}$ and report the result in Table $14 .^{22}$ We find that the coefficient on the new-benchmark dummy is statistically significantly positive except for the noisy $30 \mathrm{Y}$ sector. This indicates that whenever a new benchmark bond is introduced, there is a higher price impact of the new benchmark bond at month $t$ relative to that of the old benchmark at month $t-1$.

However, we do not think this result is sufficient to explain our main findings. Even with the new-benchmark dummy considered, the coefficient on $\triangle \mathrm{MWD} / \mathrm{GDP}$ is still statistically significant and the size of the coefficient is little changed compared to what is reported in Table 4. Moreover, the coefficient on the interaction term is not statistically significant either, indicating that the new-benchmark effect may contribute to a higher price impact on average but does not contribute to explaining the relationship between debt supply and price impact.

\footnotetext{
${ }^{21}$ One technical detail to mention is that here the regressor is still the 3-month moving average of debt supply changes. We also test with regressors with monthly changes and find no statistically significant positive relationship either.

${ }^{22}$ If the bond becomes the benchmark after the 20th day of the month, we consider the next month also as the new benchmark month.
} 


\subsection{Seasonality effect}

We also hypothesize that it is possible that there is a common holiday season in the primary and secondary markets, which means that statistically speaking, bond market issuance takes place more often before summer vacation or the end-of-year holiday season. If true, this implies that the higher price impact in the secondary market is not due to the large issuance per se, but rather to the statistical coincidence between primary issuance and secondary market trading seasons.

We test this hypothesis by removing July, August, and December from our sample. These three months are typically viewed as the holiday or vacation months such that there might be light trading in the market. As shown in Table 15, while with a smaller sample, the coefficients for $2 \mathrm{Y}$ and $5 \mathrm{Y}$ become smaller and insignificant, the results are intact for the $10 \mathrm{Y}$ and $30 \mathrm{Y}$ sectors. Therefore, the seasonality effect cannot explain our main findings either.

\section{Concluding Remarks}

In this paper, we investigate whether there is any impact from government debt supply to the bond market liquidity condition. We find that a higher maturity-weighted debt issuance leads to a higher price impact, especially in the long-term sector. Furthermore, the relationship is statistically and economically significant and robust across different measures of dependent and predictive variables and different model specifications. We argue that a combination of dealers' limited risk-bearing capacity and "security fragmentation" resulting from the government benchmark-building debt issuance strategy explains our empirical findings.

Showing that the government debt supply can have a non-negligible impact on market liquidity, our results offer an important lesson for bond market researchers and practitioners. While it is believed that debt supply from a high-credit-rating country such as Canada improves bond market liquidity, this indeed should be so for the newly issued bond itself. For other bonds already actively circulated in the market, however, our finding indicates that the supply can impact liquidity in a negative way. A broader lesson from our study is that fiscal policy, as well as monetary policy, can play a non-negligible role in financial market stability. This echoes some of the current debates about the role fiscal policy should play in stabilizing the financial system and stimulating growth (e.g., 
see Greenwood et al., 2014).

Our paper also raises an interesting question about the proper way to measure the risks faced by dealers. Greenwood and Vayanos (2014) offer an important perspective when proposing a maturity-weighted measure to summarize the duration risks faced by dealers. However, a newly issued 10-year bond that is predominantly held by dealers should be thought of differently by investors than a bond that is similar in duration but was issued a long time ago. How to better account for this heterogeneity in bond characteristics in evaluating their impact on dealers' balance sheet risks is an important topic to study in the future.

\section{References}

Adrian, T., N. Boyarchenko, and O. Shachar (2017a). Dealer balance sheets and bond liquidity provision. Journal of Monetary Economics 89, 92-109.

Adrian, T., M. Fleming, O. Shachar, and E. Vogt (2017b). Market liquidity after the financial crisis. Annual Review of Financial Economics 9(1).

Almgren, R., C. Thum, E. Hauptmann, and H. Li (2005). Direct estimation of equity market impact. Risk 18(7), 58-62.

Amihud, Y. (2002). Illiquidity and stock returns: Cross-section and time-series effects. Journal of Financial Markets 5(1), 31-56.

Amihud, Y. and H. Mendelson (1980). Dealership market: Market-making with inventory. Journal of Financial Economics 8(1), 31-53.

Bao, J., M. O'Hara, and X. A. Zhou (2016). The Volcker rule and market-making in times of stress.

Bulusu, N. and S. Gungor (2017). The life cycle of Government of Canada Bonds in core funding markets. Bank of Canada Review 2017(Spring), 31-41.

Christensen, J. H. and J. M. Gillan (2017). Does quantitative easing affect market liquidity? Federal Reserve Bank of San Francisco.

Cimon, D. A. and C. Garriott (2016). Banking regulation and market making.

Davison, A. C. and D. V. Hinkley (1997). Bootstrap methods and their application, Volume 1. Cambridge University Press. 
D'Souza, C., C. Gaa, and J. Yang (2003). An empirical analysis of liquidity and order flow in the brokered interdealer market for government of Canada bonds. Bank of Canada.

Fleming, M. and J. Rosenberg (2008). How do treasury dealers manage their positions?

Fleming, M. J. (2003). Measuring treasury market liquidity. Economic policy review $9(3)$.

Fleming, M. J. and W. Liu (2016). Intraday pricing and liquidity effects of U.S. Treasury auctions.

Fontaine, J.-S., G. Nolin, et al. (2017). Measuring limits of arbitrage in fixed-income markets. Technical report, Bank of Canada.

Goyenko, R. Y. and A. D. Ukhov (2009). Stock and bond market liquidity: A long-run empirical analysis. Journal of Financial and Quantitative Analysis 44(01), 189212.

Gravelle, T. (1998). Buying back government bonds: mechanics and other considerations. Bank of Canada.

Gravelle, T. (1999). Liquidity of the government of Canada securities market: stylized facts and some market microstructure comparisons to the United States treasury market. Bank of Canada.

Greenwood, R., S. G. Hanson, J. S. Rudolph, and L. H. Summers (2014). Government debt management at the zero lower bound. Hutchins Center Working Papers.

Greenwood, R. and D. Vayanos (2014). Bond supply and excess bond returns. Review of Financial Studies 27(3), 663-713.

Hu, G. X., J. Pan, and J. Wang (2013). Noise as information for illiquidity. The Journal of Finance 68(6), 2341-2382.

International Monetary Fund (2015, October). Market Liquidity - Resilient or Fleeting, Volume Chapter 2. Global Financial Stability Report.

Krishnamurthy, A. and A. Vissing-Jorgensen (2013). Short-term debt and financial crises: What we can learn from U.S. Treasury supply. unpublished, Northwestern University, May.

Lawley, D. (1963). On testing a set of correlation coefficients for equality. The Annals of Mathematical Statistics 34(1), 149-151. 
Lou, D., H. Yan, and J. Zhang (2013). Anticipated and repeated shocks in liquid markets. The Review of Financial Studies 26(8), 1891-1912.

Naik, N. Y. and P. K. Yadav (2003). Risk management with derivatives by dealers and market quality in government bond markets. The Journal of Finance 58(5), 1873-1904.

Roll, R. (1984). A simple implicit measure of the effective bid-ask spread in an efficient market. The Journal of Finance 39(4), 1127-1139.

Schestag, R., P. Schuster, and M. Uhrig-Homburg (2016). Measuring liquidity in bond markets. The Review of Financial Studies 29(5), 1170-1219.

Trebbi, F. and K. Xiao (2017). Regulation and market liquidity. Management Science. Vayanos, D. and J. Wang (2013). Market liquidity: Theory and empirical evidence. In Handbook of the Economics of Finance, Volume 2, pp. 1289-1361. Elsevier. 


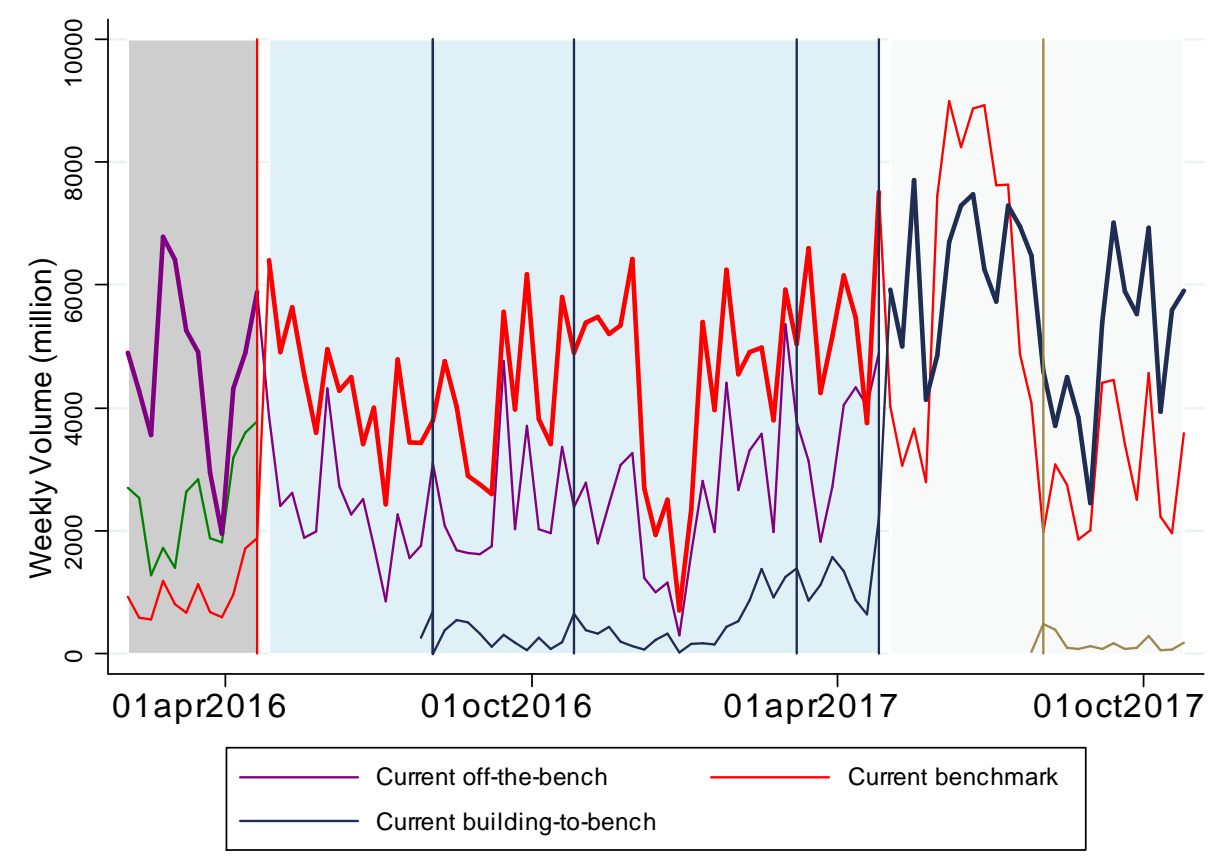

Figure 1

Illustration of Government of Canada bond issuance cycle

Solid lines indicate the trading activity of the Government of Canada benchmark, off-thebenchmark, and building-to-benchmark bonds for a given sector (e.g., 10Y). The benchmark bond is represented by the thick lines. The centre block represents the "current" period, the left block represents the "previous" period, and the right block represents the "next" period. The vertical line represents the issuance of the bond of the same colour (e.g., the red vertical line indicates the issuance of the current benchmark bond). The graph is only for illustrative purposes. 

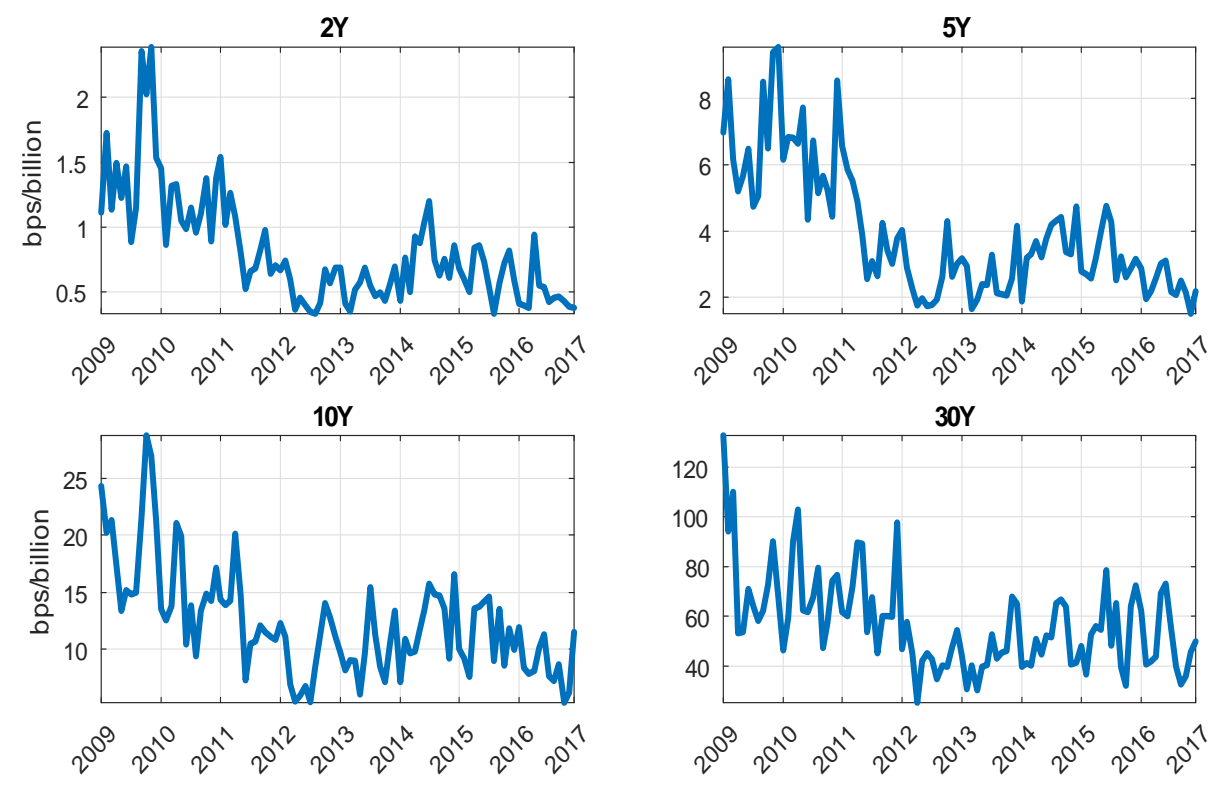

\section{Figure 2}

Time series of GoC benchmark bond illiquidity measure

The four panels indicate the time series of price impact measures of GoC benchmark bonds in 2Y, 5Y, 10Y, and 30Y sectors. The sample period is from Sep. 2009 to Aug. 2017. The price impact measure is based on the ratio between daily price dispersion aggregated over a month and monthly trading volume. The unit is bps/billion. 

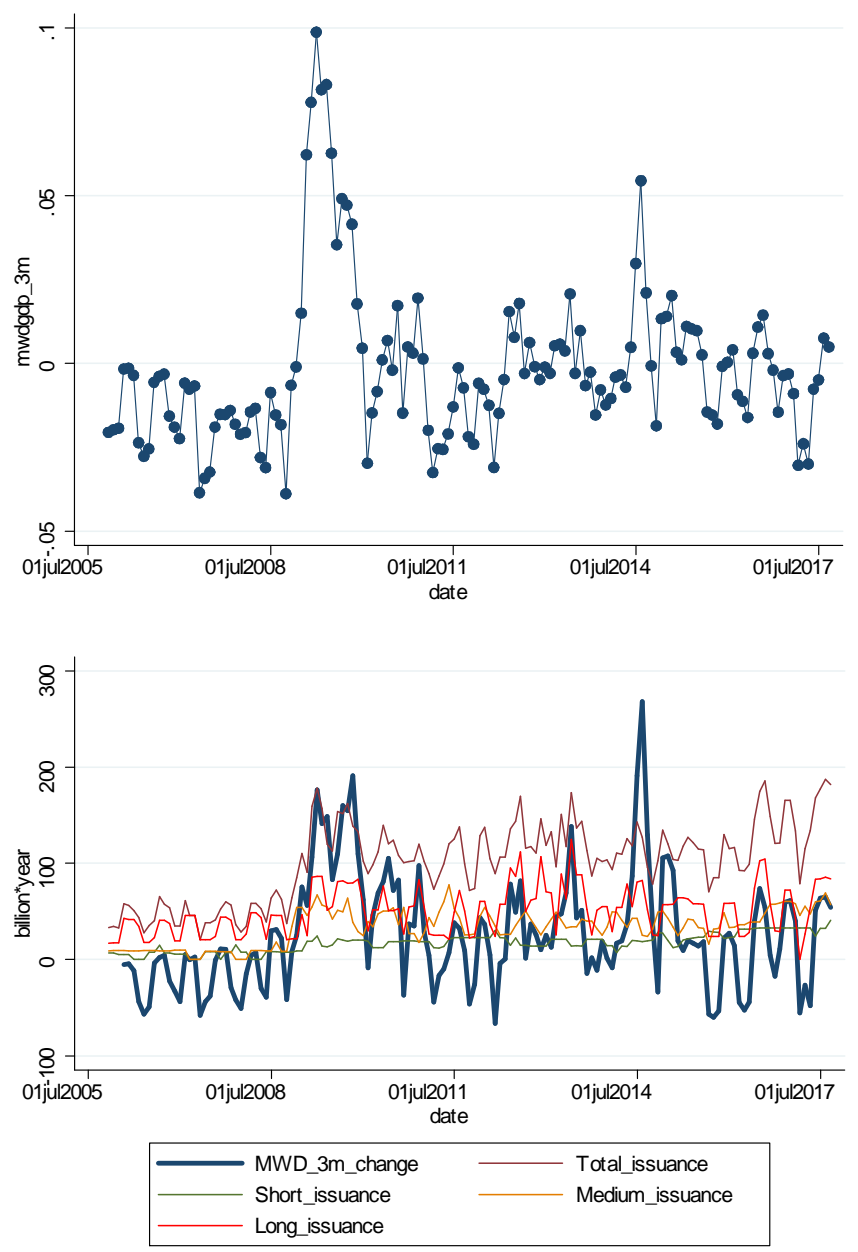

\section{Figure 3}

\section{Time series of debt supply changes}

Panel A illustrates the 3-month changes in log (MWD/GDP) measure from 2005 to 2017. Panel B illustrates the 3-month changes in MWD, public-issued duration-weighted debt (DWD) changes, and DWD changes related to short-term issuance (2Y), medium-term issuance ( $3 \mathrm{Y}$ and $5 \mathrm{Y}$ ), and long-term issuance (10Y and $30 \mathrm{Y})$. 


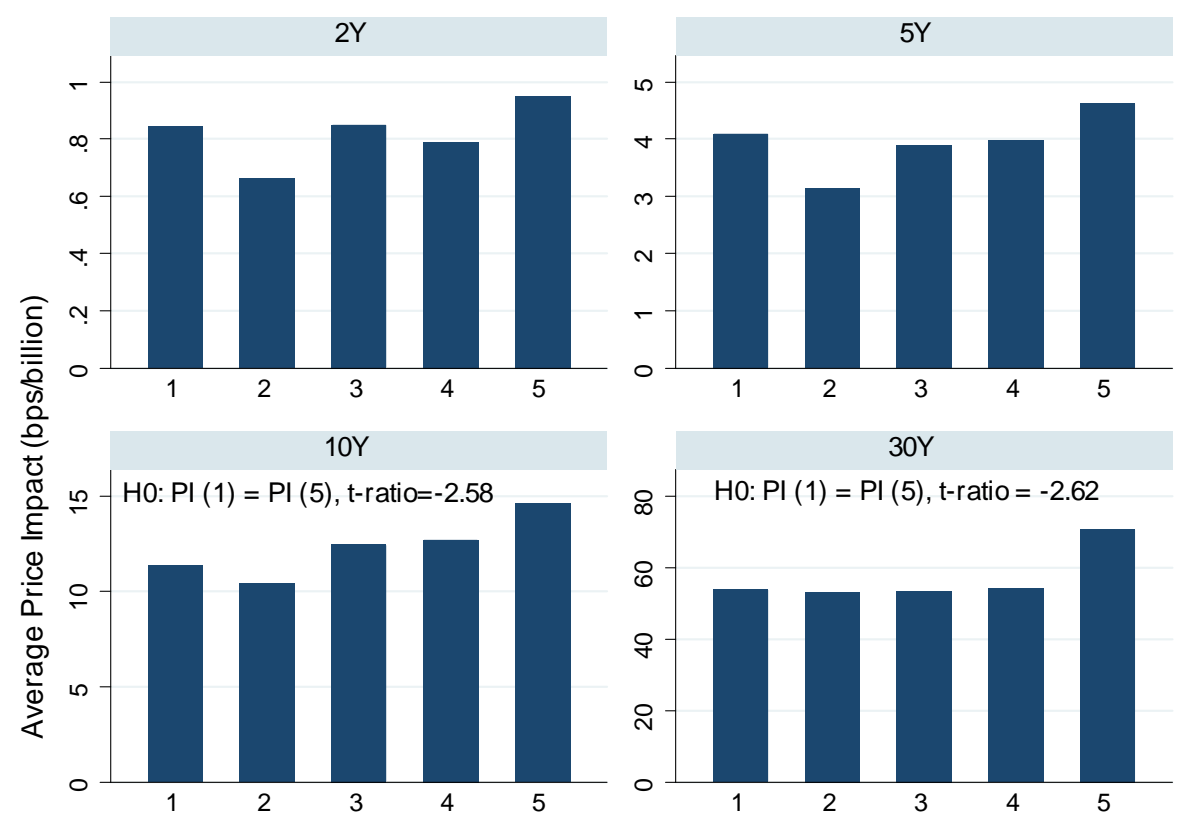

\section{Figure 4}

Average price impact over quintile groups sorted by debt supply changes

The sample period is sorted into five buckets based on the 3-month change of the maturity-weighted debt-to-GDP ratio. The bar indicates the average price impact measure for each bucket. The statistically significant test statistics would indicate the rejection of the null hypothesis that price impact measures between the highest and the lowest group are the same. 


\section{Table 1: Summary statistics of CDS trading data}

This table provides the descriptive statistics of GoC benchmark bond trading from the CDS Clearing and Depository Services Inc. and the associated liquidity measures from CDS and CanDeal. All statistics are reported as daily average over a month. The data based on CDS are from September 2009 to August 2017 and the data based on CanDeal are from July 2006 to December 2015. Trading volume, turnover, and average trade size are firstly calculated based on intraday trading data and then aggregated over a day before averaging over a month. The Roll spread, which is based on CDS data, is normalized to have the same mean as the CanDeal effective spread over the period of September 2009 to December 2015.

\begin{tabular}{|c|c|c|c|c|c|c|c|c|}
\hline & Nobs & Min & $25^{t h}$ & Median & $75^{t h}$ & Max & Mean & Std \\
\hline & & \multicolumn{7}{|c|}{$2 \mathrm{Y}$} \\
\hline Daily volume (\$bn) & 96 & 1.59 & 2.46 & 2.85 & 3.25 & 6.00 & 2.98 & 0.81 \\
\hline Daily turnover (\%) & 96 & 9.38 & 17.43 & 20.96 & 25.96 & 42.09 & 22.33 & 6.51 \\
\hline Average trade size $(\$ \mathrm{~mm})$ & 96 & 17.27 & 22.61 & 25.18 & 27.16 & 50.49 & 25.40 & 4.69 \\
\hline Price impact (bps/bn) & 96 & 0.33 & 0.51 & 0.69 & 1.02 & 2.39 & 0.82 & 0.42 \\
\hline Roll spread (bps) & 96 & 0.37 & 0.39 & 0.66 & 1.16 & 2.36 & 0.85 & 0.43 \\
\hline \multirow[t]{2}{*}{ CanDeal eff. spread (bps) } & 114 & 0.49 & 0.76 & 1.00 & 1.23 & 1.99 & 1.02 & 0.31 \\
\hline & & \multicolumn{7}{|c|}{$5 \mathrm{Y}$} \\
\hline Daily volume (\$bn) & 96 & 0.94 & 1.80 & 2.21 & 2.64 & 4.36 & 2.24 & 0.61 \\
\hline Daily turnover (\%) & 96 & 6.24 & 16.03 & 19.96 & 23.95 & 31.83 & 19.97 & 5.69 \\
\hline Average trade size $(\$ \mathrm{~mm})$ & 96 & 10.28 & 13.29 & 14.44 & 15.70 & 25.11 & 14.72 & 2.27 \\
\hline Price impact (bps/bn) & 96 & 1.51 & 2.55 & 3.29 & 4.93 & 9.55 & 3.94 & 1.91 \\
\hline Roll spread (bps) & 96 & 1.14 & 1.88 & 2.32 & 2.85 & 4.80 & 2.40 & 0.70 \\
\hline \multirow[t]{2}{*}{ CanDeal eff. spread (bps) } & 114 & 1.50 & 2.18 & 2.56 & 2.94 & 5.28 & 2.62 & 0.64 \\
\hline & & \multicolumn{7}{|c|}{$10 \mathrm{Y}$} \\
\hline Daily volume (\$bn) & 96 & 0.55 & 1.07 & 1.32 & 1.55 & 2.54 & 1.31 & 0.34 \\
\hline Daily turnover (\%) & 96 & 3.12 & 8.27 & 10.47 & 12.16 & 18.33 & 10.41 & 3.16 \\
\hline Average trade size $(\$ \mathrm{~mm})$ & 96 & 6.63 & 8.46 & 9.06 & 9.98 & 15.07 & 9.33 & 1.48 \\
\hline Price impact (bps/bn) & 96 & 5.35 & 8.99 & 11.52 & 14.30 & 28.82 & 12.32 & 4.64 \\
\hline Roll spread (bps) & 96 & 2.63 & 2.66 & 3.78 & 4.37 & 5.98 & 3.94 & 0.82 \\
\hline \multirow[t]{2}{*}{ CanDeal eff. spread (bps) } & 114 & 2.38 & 3.45 & 4.03 & 4.43 & 6.26 & 4.03 & 0.85 \\
\hline & & \multicolumn{7}{|c|}{$30 \mathrm{Y}$} \\
\hline Daily volume (\$bn) & 96 & 0.16 & 0.33 & 0.44 & 0.53 & 0.79 & 0.44 & 0.12 \\
\hline Daily turnover (\%) & 96 & 1.14 & 2.20 & 2.80 & 3.35 & 5.91 & 2.85 & 0.88 \\
\hline Average trade size $(\$ \mathrm{~mm})$ & 96 & 2.87 & 3.54 & 3.97 & 4.37 & 8.24 & 4.02 & 0.69 \\
\hline Price impact (bps/bn) & 96 & 25.39 & 43.04 & 53.56 & 65.74 & 132.64 & 57.02 & 18.80 \\
\hline Roll spread (bps) & 96 & 3.94 & 5.99 & 6.75 & 7.51 & 9.73 & 6.79 & 1.18 \\
\hline CanDeal eff. spread (bps) & 114 & 4.25 & 5.93 & 6.61 & 7.46 & 12.65 & 6.88 & 1.48 \\
\hline
\end{tabular}




\section{Table 2: Correlation in liquidity measures}

This table reports the monthly correlation of different liquidity measures such as the Amihud (2002) price impact measure, Roll (1984) bid-ask spread, and effective bid-ask spread across different sectors. The sample period is from September 2009 to December 2015.

\begin{tabular}{|c|c|c|c|c|c|c|c|c|c|c|c|c|}
\hline & \multicolumn{4}{|c|}{ PI } & \multicolumn{4}{|c|}{ Roll } & \multicolumn{4}{|c|}{ Eff.Spread } \\
\hline & $2 \mathrm{Y}$ & $5 \mathrm{Y}$ & $10 \mathrm{Y}$ & $30 \mathrm{Y}$ & $2 \mathrm{Y}$ & $5 \mathrm{Y}$ & $10 \mathrm{Y}$ & $30 \mathrm{Y}$ & $2 \mathrm{Y}$ & $5 \mathrm{Y}$ & $10 \mathrm{Y}$ & $30 \mathrm{Y}$ \\
\hline PI_2Y & 1 & & & & & & & & & & & \\
\hline PI_5Y & 0.88 & 1 & & & & & & & & & & \\
\hline $\mathrm{PI}{ }_{-} 10 \mathrm{Y}$ & 0.81 & 0.82 & 1 & & & & & & & & & \\
\hline PI_30Y & 0.53 & 0.63 & 0.68 & 1 & & & & & & & & \\
\hline Roll_2Y & 0.83 & 0.81 & 0.68 & 0.60 & 1 & & & & & & & \\
\hline Roll_5Y & 0.80 & 0.79 & 0.71 & 0.44 & 0.75 & 1 & & & & & & \\
\hline Roll_10Y & 0.59 & 0.61 & 0.67 & 0.42 & 0.55 & 0.81 & 1 & & & & & \\
\hline Roll_30Y & 0.30 & 0.26 & 0.32 & 0.24 & 0.30 & 0.57 & 0.76 & 1 & & & & \\
\hline ES_2Y & 0.64 & 0.68 & 0.49 & 0.52 & 0.76 & 0.62 & 0.33 & 0.03 & 1 & & & \\
\hline $\mathrm{ES} \_5 \mathrm{Y}$ & 0.71 & 0.79 & 0.62 & 0.60 & 0.74 & 0.74 & 0.57 & 0.28 & 0.74 & 1 & & \\
\hline $\mathrm{ES} \_10 \mathrm{Y}$ & 0.61 & 0.60 & 0.59 & 0.26 & 0.54 & 0.76 & 0.70 & 0.43 & 0.28 & 0.54 & 1 & \\
\hline ES_30Y & 0.50 & 0.52 & 0.53 & 0.44 & 0.54 & 0.70 & 0.75 & 0.61 & 0.30 & 0.59 & 0.71 & 1 \\
\hline
\end{tabular}

\section{Table 3: Descriptive statistics for macro factors}

The term spread is defined as the month-end difference between Canadian 10Y zero-coupon yield and 3-month zero-coupon yield. The TED is defined as the difference between interest rates on interbank loans and on U.S. T-bills. VIX is defined as the monthly average CBOT VIX index. CDOR spread is the difference between the Canadian interbank loan rate and the Canadian 3-month interest rate. Swap spread is defined as the difference between the 10Y Canadian swap rate and the $10 \mathrm{Y}$ Canadian constant maturity yield. Short rate is defined as the 3-month Canadian Treasury bill yield.

\begin{tabular}{ccccccccc}
\hline & Nobs & Min & $25^{\text {th }}$ & Median & $75^{\text {th }}$ & Max & Mean & Std \\
\hline Macro variables \\
\hline Term spread (\%) & 96 & 0.55 & 0.97 & 1.23 & 1.76 & 3.71 & 1.50 & 0.78 \\
TED (bps) & 96 & 12 & 14 & 24 & 36 & 56 & 28 & 11 \\
VIX(\%) & 96 & 10.26 & 13.97 & 16.23 & 20.17 & 36.53 & 17.61 & 5.48 \\
CDOR spread (bps) & 96 & 19 & 28 & 34 & 38 & 56 & 34 & 8 \\
Swap spread (bps) & 96 & 9.65 & 24.98 & 34.76 & 43.73 & 51.39 & 34.39 & 10.59 \\
Short rate (\%) & 96 & 0.12 & 0.52 & 0.89 & 0.99 & 1.13 & 0.75 & 0.27 \\
\hline
\end{tabular}




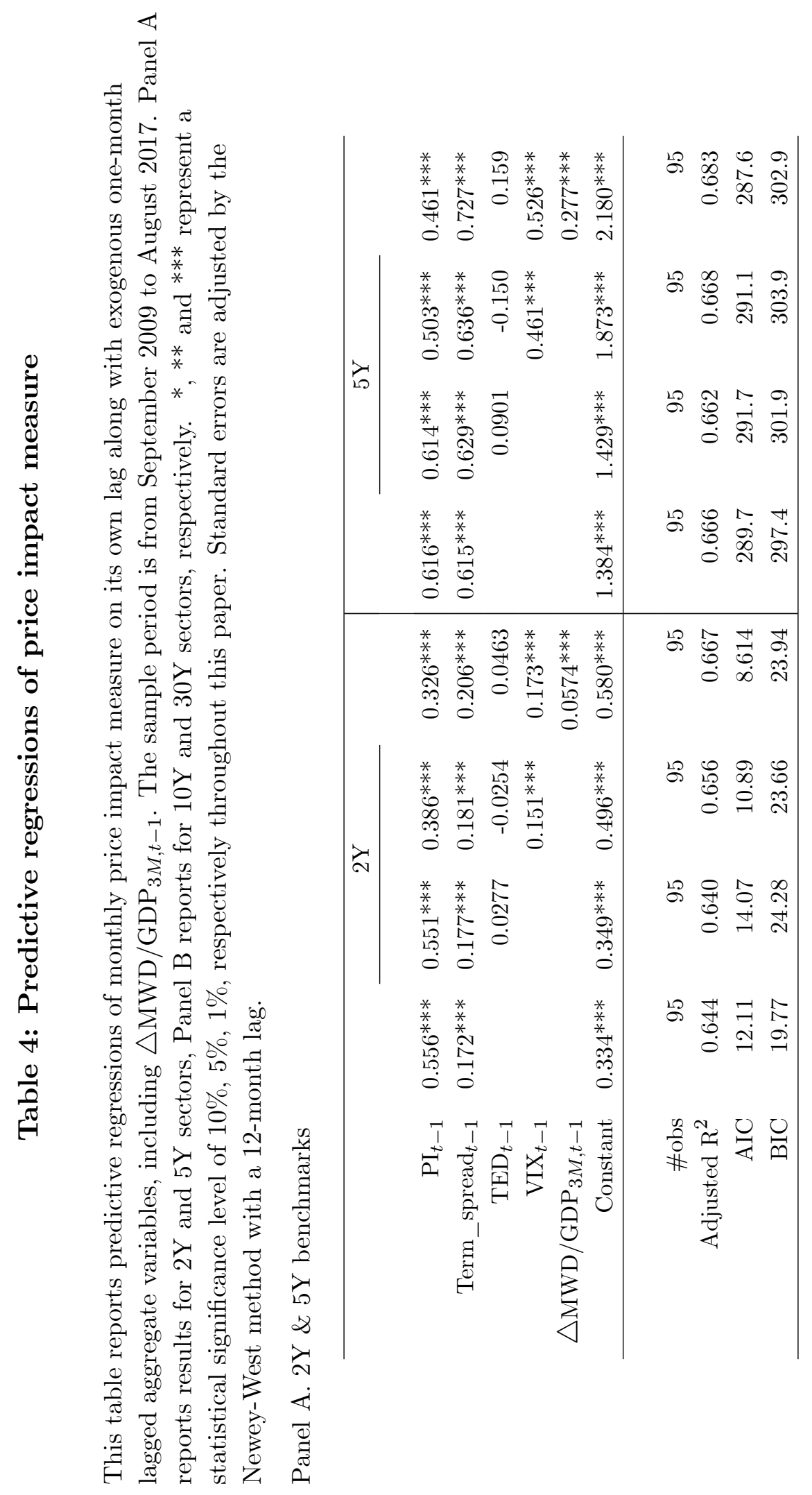




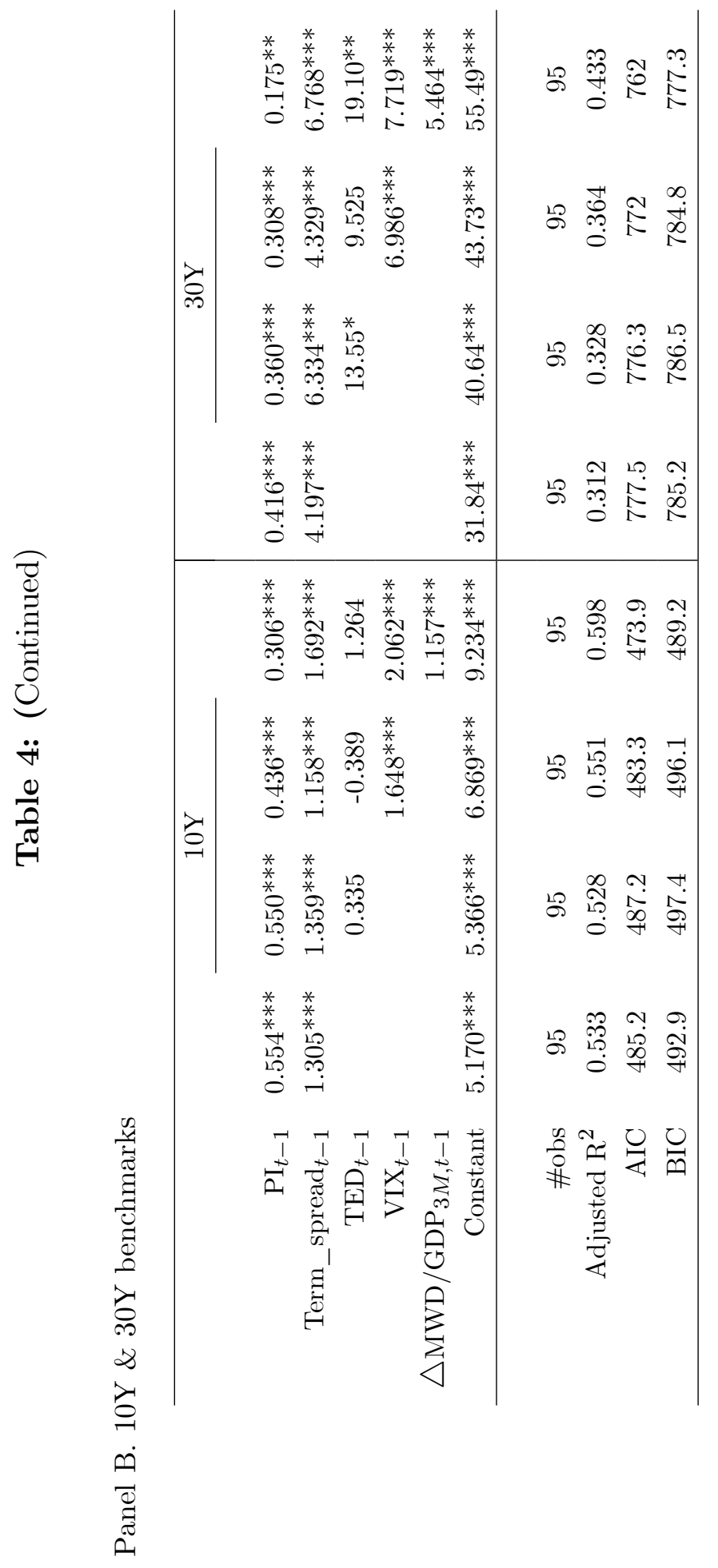




\section{Table 5: Predictive regressions with sector-level debt supply measure}

The regression is conducted with a sector-level debt supply measure. Iss_short ${ }_{3 M, t-1}$ and Iss_med ${ }_{3 M, t-1}$ represent the 3 -month changes of the duration-weighted debt issuance in the short $(2 \mathrm{Y})$ and medium (3Y \& $5 \mathrm{Y})$ sectors, respectively. Iss_long $3 M, t-1$ represents the 3 -month changes of the long sector duration-weighted issuance (10Y and 30Y), respectively. Panel A reports results for $2 \mathrm{Y}$ and $5 \mathrm{Y}$ sectors, Panel B reports results for $10 \mathrm{Y}$ and $30 \mathrm{Y}$ sectors, respectively.

Panel A. 2Y \& 5Y benchmarks

\begin{tabular}{|c|c|c|c|c|c|c|}
\hline \multirow[b]{2}{*}{$\mathrm{PI}_{t-1}$} & \multicolumn{3}{|c|}{$2 \mathrm{Y}$} & \multicolumn{3}{|c|}{$5 \mathrm{Y}$} \\
\hline & $0.373^{* * *}$ & $0.396^{* * *}$ & $0.358^{* * *}$ & $0.507^{* * *}$ & $0.501^{* * *}$ & $0.514^{* * *}$ \\
\hline Term_spread $t-1$ & $0.184^{* * *}$ & $0.166^{* * *}$ & $0.200^{* * *}$ & $0.632^{* * *}$ & $0.630^{* * *}$ & $0.676^{* * *}$ \\
\hline $\mathrm{TED}_{t-1}$ & 0.0833 & -0.108 & 0.0226 & 0.201 & -0.198 & 0.0451 \\
\hline $\mathrm{VIX}_{t-1}$ & $0.143^{* * *}$ & $0.176^{* * *}$ & $0.168^{* * *}$ & $0.409 * * *$ & $0.480^{* * *}$ & $0.465^{* * *}$ \\
\hline Iss_short $3 M, t-1$ & -0.0377 & & & -0.123 & & \\
\hline Iss_med $3 M, t-1$ & & 0.0488 & & & 0.0277 & \\
\hline Iss_long $3 M, t-1$ & & & $0.0519^{* * *}$ & & & $0.217^{* * *}$ \\
\hline Constant & $0.552^{* * *}$ & $0.460 * * *$ & $0.542^{* * *}$ & $1.997^{* * *}$ & $1.864^{* * *}$ & $1.910 * * *$ \\
\hline \#obs & 95 & 95 & 95 & 95 & 95 & 95 \\
\hline
\end{tabular}

Panel B. 10Y \& 30Y benchmarks

\begin{tabular}{rcccccc}
\hline & \multicolumn{5}{c}{$10 \mathrm{Y}$} & \multicolumn{3}{c}{$30 \mathrm{Y}$} \\
\cline { 2 - 7 } $\mathrm{PI}_{t-1}$ & $0.428^{* * *}$ & $0.430^{* * *}$ & $0.403^{* * *}$ & $0.302^{* * *}$ & $0.305^{* * *}$ & $0.277^{* * *}$ \\
Term_spread $t-1$ & $1.177^{* * *}$ & $1.055^{* *}$ & $1.432^{* *}$ & $4.395^{* * *}$ & $3.973^{* * *}$ & $5.676^{* * *}$ \\
$\mathrm{TED}_{t-1}$ & 0.520 & -1.098 & 0.418 & 12.74 & 7.195 & $14.10^{* *}$ \\
VIX $_{t-1}$ & $1.563^{* * *}$ & $1.925^{* * *}$ & $1.862^{* * *}$ & $6.645^{* * *}$ & $7.865^{* * *}$ & $7.719^{* * *}$ \\
Iss_short $3 M, t-1$ & -0.312 & & & -1.075 & & \\
Iss_med Is $_{3, t-1}$ & & 0.430 & & & 1.434 & \\
Iss_long & & & & $4.337^{* * *}$ \\
Constant & $7.331^{* * *}$ & $6.711^{* * *}$ & $7.643^{* * *}$ & $45.38^{* * *}$ & $43.17^{* * *}$ & $47.53^{* * *}$ \\
\#obs & 95 & 95 & 95 & 95 & 95 & 95 \\
\hline
\end{tabular}




\section{Table 6: Predictive regressions of trading volume and price dispersion}

This table reports predictive regression results with the dependent variables being either the log of the daily trading volume of benchmark bonds or the average daily price dispersion between top and bottom quintile daily prices over a month (the numerator in Equation 2).

\begin{tabular}{|c|c|c|c|c|}
\hline & $2 \mathrm{Y}$ & $5 \mathrm{Y}$ & $10 \mathrm{Y}$ & $30 \mathrm{Y}$ \\
\hline & \multicolumn{4}{|c|}{ (Log) trading volume } \\
\hline Volume $_{t-1}$ & $0.416^{* * *}$ & $0.337^{* * *}$ & $0.188^{* *}$ & $0.330 * * *$ \\
\hline Term_spread $t-1$ & -0.013 & $-0.103^{* * *}$ & $-0.114^{* * *}$ & $-0.113^{* * *}$ \\
\hline $\mathrm{TED}_{t-1}$ & $0.208^{*}$ & -0.034 & 0.045 & -0.167 \\
\hline $\operatorname{VIX}_{t-1}$ & $-0.111^{* * *}$ & $-0.154^{* * *}$ & $0.158^{* * *}$ & $-0.129 * * *$ \\
\hline$\triangle \mathrm{MWD} / \mathrm{GDP}_{3 M, t-1}$ & $-0.059^{* * *}$ & $-0.052^{* * *}$ & $-0.062^{* * *}$ & $-0.057^{* *}$ \\
\hline \multirow[t]{2}{*}{ Constant } & $2.459^{* * *}$ & $2.491^{* * *}$ & $2.661^{* * *}$ & $1.372^{* * *}$ \\
\hline & \multicolumn{4}{|c|}{ Price dispersion } \\
\hline Price dispersion $_{t-1}$ & $0.460 * * *$ & $0.313^{* * *}$ & $0.416^{* * *}$ & 0.076 \\
\hline Term_spread ${ }_{t-1}$ & $0.085^{* * *}$ & $0.128^{*}$ & 0.054 & -0.089 \\
\hline $\mathrm{TED}_{t-1}$ & 0.050 & -0.118 & 0.212 & 0.606 \\
\hline $\operatorname{VIX}_{t-1}$ & 0.010 & 0.080 & 0.017 & -0.101 \\
\hline$\triangle \mathrm{MWD} / \mathrm{GDP}_{3 M, t-1}$ & 0.00 & 0.027 & 0.098 & 0.082 \\
\hline Constant & $0.272^{* * *}$ & 1.082 & $1.906^{* * *}$ & $4.467^{* * *}$ \\
\hline \#obs & 95 & 95 & 95 & 95 \\
\hline
\end{tabular}




\section{Table 7: Predictive regressions with alternative debt supply measure}

$\triangle \mathrm{MWD}_{3 M, t}$ represents the 3-month changes in maturity-weighted government outstanding debt. Issuance_3M represents the 3-month changes in MWD related to public debt issuance.

Panel A. 2Y \& 5 Y benchmarks

\begin{tabular}{rcccc}
\hline & \multicolumn{2}{c}{$2 \mathrm{Y}$} & \multicolumn{2}{c}{$5 \mathrm{Y}$} \\
\cline { 2 - 5 } $\mathrm{PI}_{t-1}$ & $0.340^{* * *}$ & $0.357^{* * *}$ & $0.494^{* * *}$ & $0.505^{* * *}$ \\
Term_spread & $0.178^{* * *}$ & $0.186^{* * *}$ & $0.598^{* * *}$ & $0.627^{* * *}$ \\
$\mathrm{TED}$ & 0.0178 & -0.0783 & -0.0216 & -0.334 \\
$\mathrm{VIX}_{-}$level & $0.177^{* * *}$ & $0.196^{* * *}$ & $0.501^{* * *}$ & $0.566^{* * *}$ \\
$\triangle \mathrm{MWD}_{3 M, t-1}$ & $0.0569^{* * *}$ & & $0.189^{* *}$ & \\
Issuance_total & & $0.0624^{* *}$ & & $0.209^{* * *}$ \\
Constant $_{\text {Conyyy}}$ & $0.561^{* * *}$ & $0.508^{* * *}$ & $1.982^{* * *}$ & $1.811^{* * *}$ \\
\#obs & 95 & 95 & 95 & 95 \\
\hline
\end{tabular}

Panel B. 10Y \& 30Y benchmarks

\begin{tabular}{rcccc}
\hline & \multicolumn{2}{c}{$10 \mathrm{Y}$} & \multicolumn{2}{c}{$30 \mathrm{Y}$} \\
\cline { 2 - 5 } lag_dep & $0.370^{* * *}$ & $0.413^{* * *}$ & $0.231^{* * *}$ & $0.287^{* * *}$ \\
Term_spread $t-1$ & $1.071^{* *}$ & $1.188^{* *}$ & $3.913^{* *}$ & $4.437^{* *}$ \\
$\mathrm{TED}_{t-1}$ & 0.488 & -1.121 & $14.97^{*}$ & 6.148 \\
$\mathrm{VIX}_{t-1}$ & $2.016^{* * *}$ & $2.197^{* * *}$ & $8.197^{* * *}$ & $9.474^{* * *}$ \\
$\triangle \mathrm{MWD}_{3 M, t-1}$ & $1.038^{* * *}$ & & $5.158^{* * *}$ & \\
Issuance_total & & $0.888^{* * *}, t-1$ & & $4.410^{* * *}$ \\
Constant & $8.187^{* * *}$ & $6.962^{* * *}$ & $50.99^{* * *}$ & $44.14^{* * *}$ \\
\#obs & 95 & 95 & 95 & 95 \\
\hline
\end{tabular}




\section{Table 8: Predictive regressions with alternative price impact measure}

PI01 is defined as the ratio between the absolute return of the bond during the trading day and the daily trading volume before averaging over a month. PI02 is defined as the ratio of the spread between top quartile log price and bottom quartile log price and the daily trading volume before averaging over a month. PI03 is the same as PI02 except that when averaged over a month, weighting is based on daily trading volumes.

Panel A. 2Y \& 5 Y benchmarks

\begin{tabular}{rcccccc}
\hline & PI01 & PI02 & PI03 & PI01 & PI02 & PI03 \\
\cline { 2 - 7 } PI $_{t-1}$ & 0.0414 & $0.299^{* * *}$ & $0.351^{* * *}$ & $0.359^{* * *}$ & $0.535^{* * *}$ & $0.483^{* * *}$ \\
Term_spread $t-1$ & $0.431^{* * *}$ & $0.221^{* * *}$ & $0.205^{* * *}$ & $1.184^{* * *}$ & $0.721^{* * *}$ & $0.701^{* * *}$ \\
TED $_{t-1}$ & -0.157 & 0.0310 & 0.0251 & -0.176 & 0.134 & 0.0998 \\
VIX $_{t-1}$ & $0.522^{* * *}$ & $0.228^{* * *}$ & $0.184^{* * *}$ & $1.565^{* * *}$ & $0.599^{* * *}$ & $0.610^{* * *}$ \\
$\triangle \mathrm{MWD} / \mathrm{GDP}_{3 M, t-1}$ & $0.104^{* *}$ & $0.0950^{* * *}$ & $0.0778^{* * *}$ & $0.519^{* * *}$ & $0.298^{* * *}$ & $0.270^{* *}$ \\
$\mathrm{Constant}$ & $1.394^{* * *}$ & $0.670^{* * *}$ & $0.573^{* * *}$ & $4.224^{* * *}$ & $2.124^{* * *}$ & $2.164^{* * *}$ \\
\hline & & & & & & \\
\#obs & 95 & 95 & 95 & 95 & 95 & 95 \\
\hline
\end{tabular}

Panel B. 10Y \& 30Y benchmarks

\begin{tabular}{|c|c|c|c|c|c|c|}
\hline & PI01 & PI02 & PI03 & PI01 & PI02 & PI03 \\
\hline & & $10 \mathrm{Y}$ & & & $30 \mathrm{Y}$ & \\
\hline $\mathrm{PI}_{t-1}$ & -0.0105 & $0.216^{*}$ & $0.182^{*}$ & -0.0185 & -0.0153 & $0.254^{* * *}$ \\
\hline Term_spread ${ }_{t-1}$ & 0.999 & $1.803^{* * *}$ & $2.006^{* * *}$ & -66.45 & -66.27 & $7.085^{* * *}$ \\
\hline $\mathrm{TED}_{t-1}$ & -2.217 & 0.399 & 1.244 & -271.6 & -275.8 & $17.22^{* *}$ \\
\hline $\operatorname{VIX}_{t-1}$ & $5.482^{* * *}$ & $2.134^{* * *}$ & $2.596^{* * *}$ & 30.35 & 21.05 & $5.877^{* * *}$ \\
\hline$\triangle \mathrm{MWD} / \mathrm{GDP}_{3 M, t-1}$ & $1.745^{* * *}$ & $1.252^{* * *}$ & $1.337^{* * *}$ & -4.130 & -5.084 & $5.117^{* * *}$ \\
\hline Constant & $19.31^{* * *}$ & $10.95^{* * *}$ & $11.15^{* * *}$ & $101.5^{* *}$ & $73.07^{*}$ & $51.32^{* * *}$ \\
\hline \#obs & 95 & 95 & 95 & 95 & 95 & 95 \\
\hline
\end{tabular}




\section{Table 9: Predictive regressions with more control variables for long-term sectors}

CDOR spread is the difference between the Canadian interbank loan rate and the Canadian 3 -month interest rate. Swap spread is defined as the difference between the 10Y Canadian swap rate and the $10 \mathrm{Y}$ Canadian constant maturity yield. Short rate is defined as the 3-month Canadian Treasury bill yield.

\begin{tabular}{|c|c|c|c|c|c|c|}
\hline \multirow[b]{2}{*}{$\mathrm{PI}_{t-1}$} & \multicolumn{3}{|c|}{$10 \mathrm{Y}$} & \multicolumn{3}{|c|}{$30 \mathrm{Y}$} \\
\hline & $0.310^{* * *}$ & $0.306^{* * *}$ & $0.306^{* * *}$ & $0.197^{* *}$ & $0.158^{*}$ & $0.162^{* *}$ \\
\hline Term_spread ${ }_{t-1}$ & $1.744^{* * *}$ & $1.625^{* *}$ & $1.771^{* *}$ & $7.294^{* * *}$ & $8.291^{* * *}$ & $5.946^{* * *}$ \\
\hline $\mathrm{TED}_{t-1}$ & 0.765 & 1.043 & 1.464 & 12.15 & $23.92^{* * *}$ & $17.01^{*}$ \\
\hline $\operatorname{VIX}_{t-1}$ & $2.030 * * *$ & $2.085^{* * *}$ & $2.071^{* * *}$ & $7.315^{* * *}$ & $7.430^{* * *}$ & $7.713^{* * *}$ \\
\hline$\triangle \mathrm{MWD} / \mathrm{GDP}_{3 M, t-1}$ & $1.201^{* * *}$ & $1.144^{* * *}$ & $1.162^{* * *}$ & $5.938^{* * *}$ & $5.842^{* * *}$ & $5.499^{* * *}$ \\
\hline CDOR_spread ${ }_{t-1}$ & 0.249 & & & $3.206^{*}$ & & \\
\hline $\mathrm{SR}_{t-1}$ & & -0.0975 & & & 1.859 & \\
\hline swap_spread $_{t-1}$ & & & 0.0995 & & & -1.268 \\
\hline Constant & $8.958^{* * *}$ & $9.163^{* * *}$ & $9.317^{* * *}$ & $51.02^{* * *}$ & $58.25^{* * *}$ & $55.50^{* * *}$ \\
\hline \#obs & 95 & 95 & 95 & 95 & 95 & 95 \\
\hline
\end{tabular}




\section{Table 10: Robustness tests}

Panel A reports the result of specifying ARMA models for the price impact measures with all control variables as exogenous variables. Panel B reports the result of applying the bootstrap percentile method to calculate the confidence interval of the regression coefficient on $\triangle \mathrm{MWD} / \mathrm{GDP}_{3 M, t-1}$. The number of draws is 10,000 . The first two columns are based on drawing a fixed-length (12-month or 24-month) block to conduct the non-parametric bootstrap; the third and fourth columns are based on geometrically distributed block length centering around 12 and 24 months; the last column is based on the parametric bootstrap method.

Panel A. ARMA regression

\begin{tabular}{|c|c|c|c|c|c|c|}
\hline & $\operatorname{ARMA}(1,1)$ & $\operatorname{ARMA}(2,1)$ & $\operatorname{ARMA}(2,2)$ & $\operatorname{ARMA}(1,1)$ & $\operatorname{ARMA}(2,1)$ & $\operatorname{ARMA}(2,2)$ \\
\hline & \multicolumn{3}{|c|}{$2 \mathrm{Y}$} & \multicolumn{3}{|c|}{$5 \mathrm{Y}$} \\
\hline Term_spread $_{t-1}$ & $0.243^{* * *}$ & $0.262^{* * *}$ & $0.286^{* * *}$ & 0.604 & 0.684 & 0.611 \\
\hline $\mathrm{TED}_{t-1}$ & 0.066 & 0.064 & 0.045 & 0.551 & 0.578 & 0.53 \\
\hline $\operatorname{VIX}_{t-1}$ & $0.219^{* *}$ & $0.214^{* * *}$ & $0.211^{* * *}$ & $0.545^{*}$ & $0.646^{*}$ & $0.582^{*}$ \\
\hline$\triangle \mathrm{MWD} / \mathrm{GDP}_{3 M, t-1}$ & $0.067^{* *}$ & $0.076^{* *}$ & 0.053 & $0.467^{* * *}$ & $0.487 * * *$ & $0.413^{* *}$ \\
\hline \multirow[t]{2}{*}{ Constant } & $0.845^{* * *}$ & $0.842^{* * *}$ & $0.838^{* * *}$ & $4.123^{* * *}$ & $4.141^{* * *}$ & $4.135^{* * *}$ \\
\hline & \multicolumn{3}{|c|}{$10 \mathrm{Y}$} & \multicolumn{3}{|c|}{$30 \mathrm{Y}$} \\
\hline Term_spread $_{t-1}$ & $2.671^{* * *}$ & $2.836^{* * *}$ & $2.544^{* * *}$ & $10.782^{* * *}$ & $10.862^{* * *}$ & $9.936^{* * *}$ \\
\hline $\mathrm{TED}_{t-1}$ & 3.095 & 3.402 & 2.228 & $28.652^{* * *}$ & $28.514^{* * *}$ & $26.805^{* * *}$ \\
\hline $\operatorname{VIX}_{t-1}$ & $2.669^{* * *}$ & $2.609^{* * *}$ & $2.857^{* * *}$ & $7.902^{* *}$ & $7.328^{*}$ & $9.058^{* *}$ \\
\hline$\triangle \mathrm{MWD} / \mathrm{GDP}_{3 M, t-1}$ & $1.507^{* * *}$ & $1.496^{* * *}$ & $1.447^{* * *}$ & $7.866^{* * *}$ & $8.105^{* * *}$ & $8.084^{* * *}$ \\
\hline Constant & $13.829 * * *$ & $13.936^{* * *}$ & $13.521^{* * *}$ & $69.522^{* * *}$ & $69.308^{* * *}$ & $69.027 * * *$ \\
\hline
\end{tabular}

Panel B. Bootstrap confidence interval

\begin{tabular}{cccccc}
\hline & \multicolumn{2}{c}{ Block: fixed } & \multicolumn{2}{c}{ Block: geometric } & Parametric \\
\hline & 12 month & 24 month & 12 month & 24 month & \\
\hline $2 \mathrm{Y}$ & {$[0.006,0.153]$} & {$[0.005,0.139]$} & {$[0.006,0.146]$} & {$[0.010,0.130]$} & {$[-0.000,0.110]$} \\
$5 \mathrm{Y}$ & {$[0.163,0.740]$} & {$[0.196,0.635]$} & {$[0.171,0.695]$} & {$[0.197,0.637]$} & {$[0.219,0.331]$} \\
$10 \mathrm{Y}$ & {$[1.022,2.413]$} & {$[0.876,2.185]$} & {$[0.983,2.286]$} & {$[0.969,2.085]$} & {$[0.502,1.791]$} \\
$30 \mathrm{Y}$ & {$[4.506,11.743]$} & {$[4.546,11.315]$} & {$[4.671,11.426]$} & {$[4.811,10.942]$} & {$[4.740,6.180]$} \\
\hline
\end{tabular}




\section{Table 11: Summary statistics of 1st off-the-benchmark bond}

Panel A provides the descriptive statistics of tradings in building-to-benchmark and 1st, 2nd, and 3rd off-the-benchmark bonds. The sample period is from September 2009 to August 2017. Trading volume, turnover, and average trade size are first calculated based on intraday trading data and then averaged over a month. Panel B provides the average daily correlation among the $10 \mathrm{Y}$ benchmark bonds, $10 \mathrm{Y}$ building-to-benchmark and $10 \mathrm{Y}$ off-the-benchmark bonds. The statistical test is based on Lawley's (1963) Chi test.

Panel A. Summary statistics for CDS

\begin{tabular}{|c|c|c|c|c|c|c|c|c|}
\hline & Mean & Std & Mean & Std & Mean & Std & Mean & Std \\
\hline & \multicolumn{2}{|c|}{ building } & \multicolumn{2}{|c|}{ 1st off } & \multicolumn{2}{|c|}{ 2nd off } & \multicolumn{2}{|c|}{ 3rd off } \\
\hline & \multicolumn{8}{|c|}{$2 \mathrm{Y}$} \\
\hline Daily volume (\$bn) & 0.43 & 0.37 & 0.3 & 0.1 & 0.12 & 0.05 & 0.12 & 0.06 \\
\hline Average trade size $(\$ \mathrm{~mm})$ & 27.8 & 12.0 & 24.5 & 10.0 & 19.5 & 8.1 & 18.0 & 6.8 \\
\hline \multirow[t]{2}{*}{ Price impact (bps/bn) } & 5.7 & 6.1 & 5.5 & 4.4 & 7.6 & 7.5 & 6.0 & 6.4 \\
\hline & \multicolumn{8}{|c|}{$5 \mathrm{Y}$} \\
\hline Daily volume (\$bn) & 0.29 & 0.29 & 0.32 & 0.14 & 0.19 & 0.10 & 0.16 & 0.08 \\
\hline Average trade size $(\$ \mathrm{~mm})$ & 18.9 & 6.8 & 12.1 & 2.1 & 11.6 & 3.5 & 11.4 & 3.2 \\
\hline \multirow[t]{2}{*}{ Price impact (bps/bn) } & 24.8 & 15.3 & 21.5 & 10.6 & 29.5 & 19.4 & 22.5 & 14.5 \\
\hline & \multicolumn{8}{|c|}{$10 \mathrm{Y}$} \\
\hline Daily trade volume (\$bn) & 0.22 & 0.20 & 0.56 & 0.24 & 0.24 & 0.19 & 0.16 & 0.06 \\
\hline Average trade size $(\$ \mathrm{~mm})$ & 10.6 & 2.9 & 12.0 & 2.4 & 9.7 & 2.5 & 8.1 & 1.9 \\
\hline \multirow[t]{2}{*}{ Price impact (bps/bn) } & 81.9 & 72.1 & 27.1 & 13.6 & 55.2 & 29.7 & 55.9 & 24.5 \\
\hline & \multicolumn{8}{|c|}{$30 \mathrm{Y}$} \\
\hline Daily trade volume (\$bn) & 0.05 & 0.04 & 0.07 & 0.04 & 0.05 & 0.02 & 0.05 & 0.03 \\
\hline Average trade size $(\$ \mathrm{~mm})$ & 6.1 & 3.1 & 4.9 & 1.1 & 4.8 & 1.9 & 5.9 & 3.3 \\
\hline Price impact (bps/bn) & 318.1 & 215.8 & 232.1 & 136.3 & 255.5 & 125.2 & 239.6 & 164.6 \\
\hline
\end{tabular}

Panel B. Trading activity correlation

\begin{tabular}{|c|c|c|c|}
\hline & \multicolumn{3}{|c|}{$10 \mathrm{Y}$} \\
\hline & $2009-2017$ & $2009-2013$ & $2014-2017$ \\
\hline$\rho_{\text {bench,building }}$ & 0.35 & 0.34 & 0.35 \\
\hline$\rho_{\text {bench, }, 1 s t \_o f f}$ & 0.62 & 0.62 & 0.58 \\
\hline$\rho_{\text {bench,2nd_off }}$ & 0.32 & 0.38 & 0.22 \\
\hline$\rho_{\text {bench }, 3 r d \_o f f}$ & 0.28 & 0.30 & 0.20 \\
\hline \multicolumn{4}{|c|}{$\mathrm{H} 0: \rho_{\text {bench,building }}=\rho_{\text {bench }, 1 \text { st_off }}$} \\
\hline Lawley's $\chi^{2}$ & $229.5^{* * *}$ & $150.2^{* * *}$ & $70.7^{* * *}$ \\
\hline
\end{tabular}




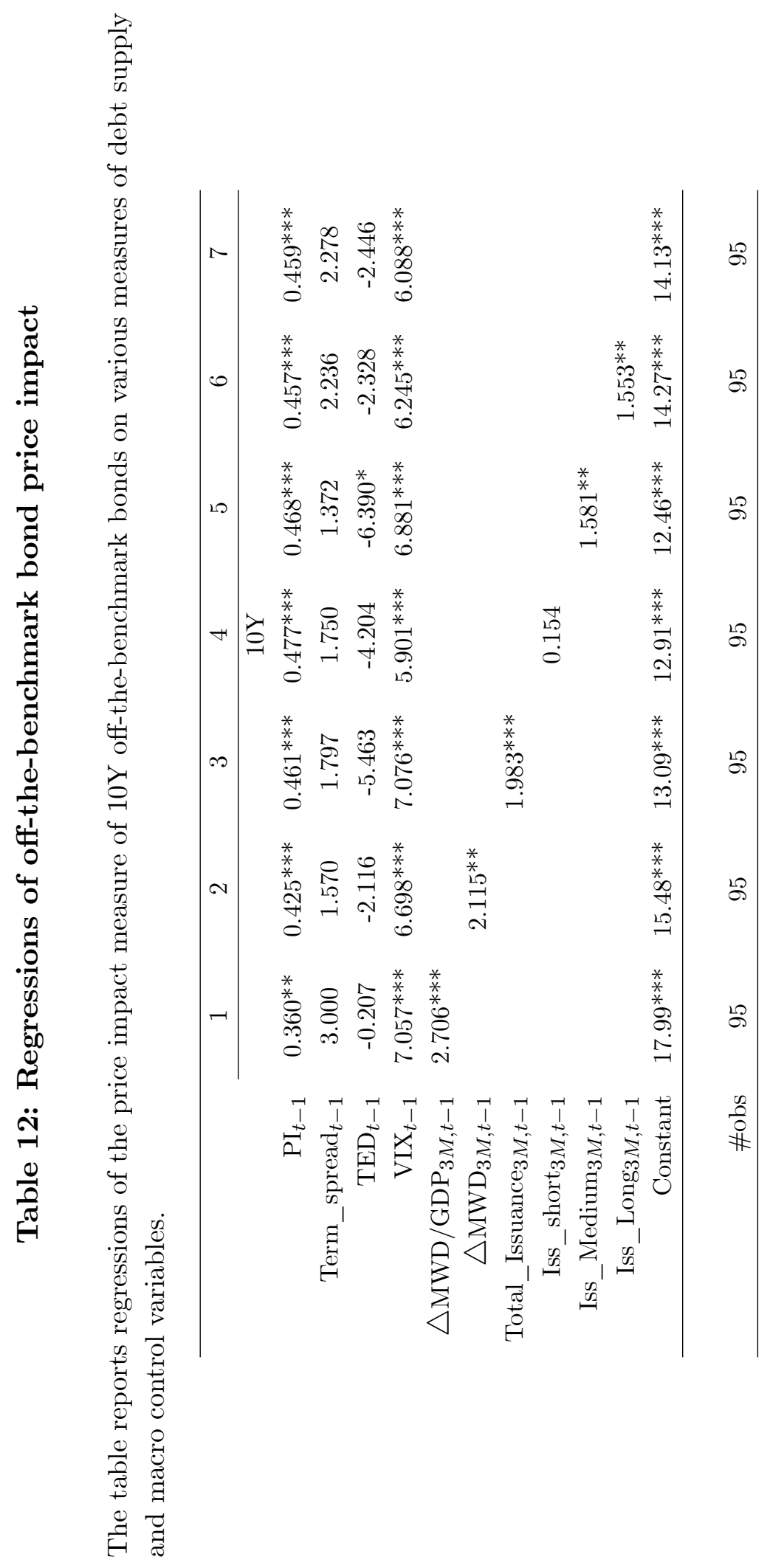




\section{Table 13: Contemporaneous regressions of trading activity on the same- month government debt issuance}

This table reports regression results of the monthly benchmark price impact measure on its own lag along with exogenous factors of the same month. The sample period is from September 2009 to August 2017. Standard errors are adjusted by the Newey-West method with a 12-month lag.

\begin{tabular}{ccccc}
\hline & \multicolumn{4}{c}{ Volume } \\
\cline { 2 - 5 } & $2 \mathrm{Y}$ & $5 \mathrm{Y}$ & $10 \mathrm{Y}$ & $30 \mathrm{Y}$ \\
\cline { 2 - 5 } $\mathrm{PI}_{t-1}$ & $0.528^{* * *}$ & $0.523^{* * *}$ & $0.342^{* * *}$ & $0.457^{* * *}$ \\
Term_spread $_{t}$ & $-0.0321^{*}$ & $-0.0711^{* * *}$ & $-0.105^{* * *}$ & $-0.120^{* * *}$ \\
$\mathrm{TED}_{t}$ & 0.0769 & -0.0436 & -0.0443 & $-0.220^{* *}$ \\
VIX $_{t}$ & -0.0435 & $-0.0894^{* * *}$ & $-0.0938^{* * *}$ & -0.0252 \\
$\triangle \mathrm{MWD} / \mathrm{GDP}_{3 M, t}$ & $-0.0483^{* * *}$ & $-0.0315^{*}$ & $-0.0483^{* * *}$ & $-0.0463^{* *}$ \\
Constant & $0.532^{* * *}$ & $0.343^{* * *}$ & $0.136^{* * *}$ & $-0.548^{* * *}$ \\
& & & & \\
\#obs & 95 & 95 & 95 & 95 \\
\hline
\end{tabular}

\section{Table 14: Predictive regressions with new benchmark dummy}

The dummy variable for a given sector is 1 if the new benchmark bond is introduced recently. If the benchmark is introduced after the 20th of the month, then only the next month has the benchmark dummy variable equal to 1 . If the benchmark is introduced on and before the 20th of the month, then the current month and the next both have dummy variables equal to 1 .

\begin{tabular}{rcccc}
\hline & $2 \mathrm{Y}$ & $5 \mathrm{Y}$ & $10 \mathrm{Y}$ & $30 \mathrm{Y}$ \\
\cline { 2 - 5 } $\mathrm{PI}_{t-1}$ & $0.347^{* * *}$ & $0.464^{* * *}$ & $0.353^{* * *}$ & $0.187^{* *}$ \\
Term_spread & $0.203^{* * *}$ & $0.720^{* * *}$ & $1.564^{* * *}$ & $7.016^{* * *}$ \\
$\mathrm{TED}$ & 0.0807 & 0.221 & 1.377 & $21.12^{* * *}$ \\
$\mathrm{VIX}_{-}$level & $0.169^{* *}$ & $0.557^{*}$ & $2.011^{* * *}$ & $6.941^{* *}$ \\
$\triangle \mathrm{MWD} / \mathrm{GDP}_{3 M, t-1}$ & $0.0542^{*}$ & $0.294^{* *}$ & $1.135^{* * *}$ & $4.564^{* * *}$ \\
$\mathrm{New}_{\text {bench dummy }}$ & $0.212^{* * *}$ & $0.609^{*}$ & $2.359^{* * *}$ & 4.605 \\
$\triangle \mathrm{MWD} / \mathrm{GDP}_{3 M, t-1} \times$ dummy $_{t}$ & 0.0769 & 0.0109 & 0.292 & $8.916^{*}$ \\
Constant & $0.550^{* * *}$ & $2.121^{* * *}$ & $8.396^{* * *}$ & $55.03^{* * *}$ \\
\hline & & & & \\
\#obs & 95 & 95 & 95 & 95 \\
\hline
\end{tabular}


Table 15: Regression when July, August, and December are removed

This table reports regression results when July, August, and December, the three months that see relatively light trading in the market, are removed from the sample. The standard errors are reported without Newey-West adjustment.

\begin{tabular}{rcccc}
\hline & $2 \mathrm{Y}$ & $5 \mathrm{Y}$ & $10 \mathrm{Y}$ & $30 \mathrm{Y}$ \\
\cline { 2 - 5 } $\mathrm{PI}_{t-1}$ & $0.351^{* * *}$ & $0.456^{* * *}$ & 0.167 & 0.0922 \\
Term_spread & $0.190^{* * *}$ & $0.557^{* *}$ & $1.906^{* * *}$ & $8.933^{* * *}$ \\
$\mathrm{TED}_{t-1}$ & -0.0351 & -0.466 & 1.681 & $23.02^{* * *}$ \\
$\mathrm{VIX}_{t-1}$ & $0.136^{*}$ & $0.581^{* *}$ & $2.054^{* * *}$ & $7.158^{* * *}$ \\
$\triangle \mathrm{MWD} / \mathrm{GDP}_{3 M, t-1}$ & 0.0519 & 0.164 & $1.358^{* * *}$ & $5.042^{* * *}$ \\
$\mathrm{Constant}$ & $0.499^{* * *}$ & $1.908^{* * *}$ & $10.75^{* * *}$ & $59.77^{* * *}$ \\
\hline & & & & \\
\#obs & 71 & 71 & 71 & 71 \\
\hline
\end{tabular}

